\title{
ANL/MCS-TM-155
}

\section{Querying Genomic Databases}

by

Alexandra Baehr, Ray Hagstrom, David Joerg, and Ross Overbeek

September 1991
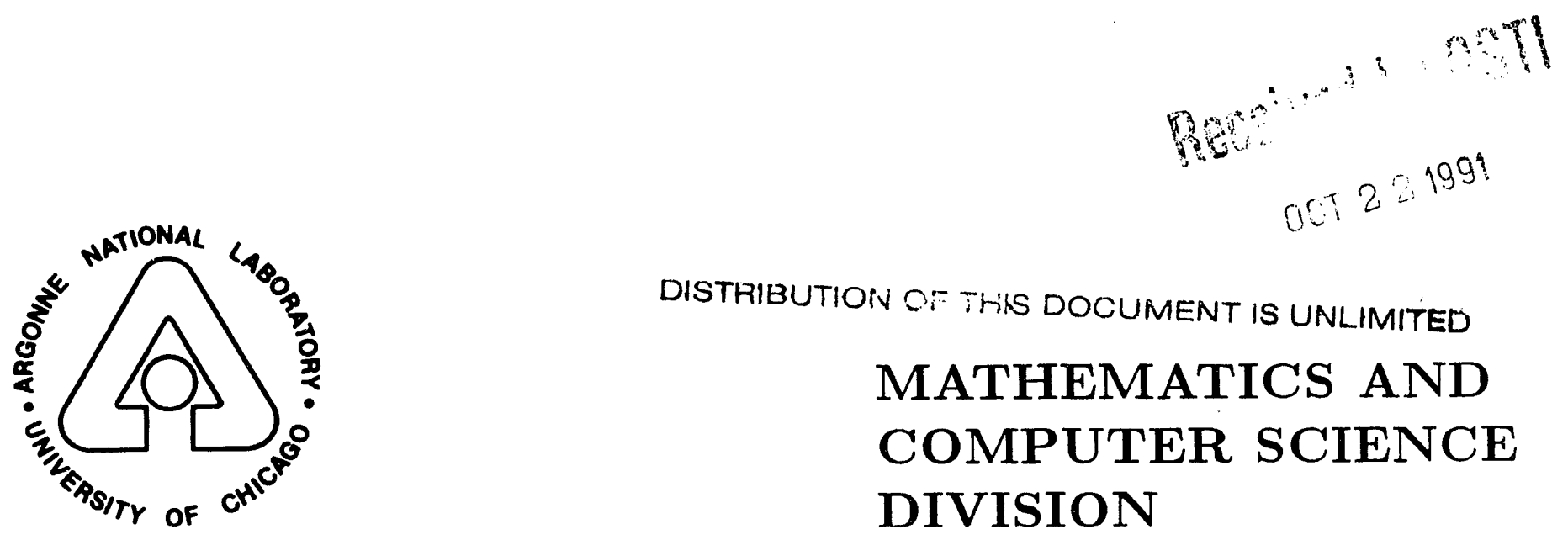

DISTHIBUTION O- FHIS DOCUMENT IS UNLIMITED 
Argonne National Laboratory, with facilities in the states of Illinois and Idaho, is owned by the United States government, and operated by The University of Chicago under the provisions of a contract with the Department of Energy.

\section{DISCLAIMER}

This report was prepared as an account of work sponsored by an agency of the United States Government. Neither the United States Government nor any agency thereof, nor any of their employees, makes any warranty, express or implied, or assumes any legal liability or responsibility for the accuracy, completeness, or usefulness of any information, apparatus, product, or process disclosed, or represents that its use would not infringe privately owned rights. Reference herein to any specific commercial product, process, or service by trade name, trademark, manufacturer, or otherwise, does not necessarily constitute or imply its endorsement, recommendation, or favoring by the United States Government or any agency thereof. The views and opinions of authors expressed herein do not necessarily state or reflect those of the United States Government or any agency thereof.

Reproduced from the best available copy.

Available to DOE and DOE contractors from the Office of Scientific and Technical Information P.O. Box 62

Oak Ridge, TN 37831

Prices available from (615) 576-8401, FTS 626-8401

Available to the public from the National Technical Information Service

U.S. Department of Commerce 5285 Port Royal Road Springfield, VA 22161 
ARGONNE NATIONAL LABORATORY

9700 South Cass Avenue

Argonne, IL 60439-4801

ANL/MCS-TM-155
ANL/MCS - TM- -155

DE92 001663

\section{Querying Genomic Databases}

by

Alexandra Baehr, Ray Hagstrom, David Joerg, and Ross Overbeek

Mathematics and Computer Science Division

Technical Memorandum No. 155

September 1991

\section{MASTER}

This work was supported by the Office of IIealth and Environmenta! Research, U.S. Department of Energy, under Contract WV-31-109-Eng-38. 


\section{Contents}

$\begin{array}{ll}\text { Abstract } & 1\end{array}$

1 Tntroduction 1

2 Locating Reference Points 1

2.1 Origin of Replication ........................... 1

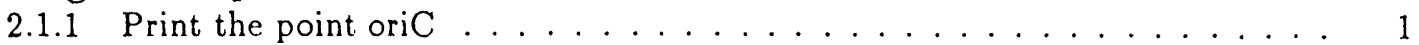

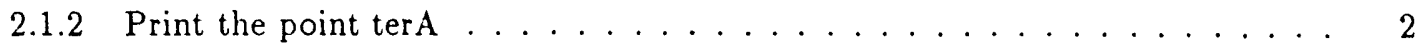

2.2 Establishing Partitions of the Genome . . . . . . . . . . . . . . . . . . . 2

2.2.1 Print 4 equal partitions of the genome . . . . . . . . . . . . . . . 2

2.2.2 Print 4 equal partitions of the genome starting at oriC . . . . . . . . . . . 2

2.2.3 Print 8 equal partitions of the genome starting at $9802 \ldots \ldots$. . . . . . 2

3 Retrieving Information on Kohara Clones 3

3.1 Locate All Kohara Clones . . . . . . . . . . . . . . . . . . . . . 3

3.1.1 Print all kohara clones in the genome . . . . . . . . . . . . . . 3

3.2 Locate Kohara Clones by Region or Landmark . . . . . . . . . . . . . . . . 3

3.2.1 Print the kohara clones in the region from $400 \mathrm{~kb}$ to $800 \mathrm{~kb} \ldots \ldots 3$

3.2.2 Print the kohara clones in the region from the start of gene thrC -5000 to the start of gene thrC ...................... 4

3.3 Locate Clones Containing Particular Nucleotide Patterns . . . . . . . . . . 4

3.3.1 Print all kohara clones that contain the pattern GATC . . . . . . . . . . 4

3.3.2 Print all (kohara clones in the region from $400 \mathrm{~kb}$ to $800 \mathrm{~kb}$ ) that contain the

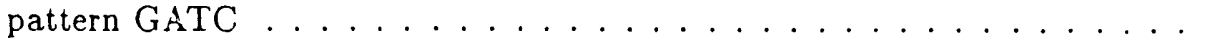

3.3.3 Let SpecialGenes be translated counterclockwise genes that contain the pit-

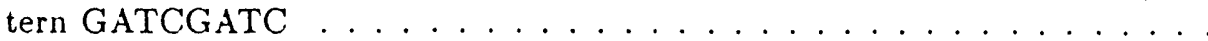

3.3.4 For each member of SpecialGenes Gene, \{print Gene; print all kohara clones that contain Gene $\ldots \ldots \ldots . \ldots \ldots$

4 Retrieving Information on Genes $\mathbf{5}$

4.1 Locate Genes by Id . . . . . . . . . . . . . . . . . . . . . . . 5

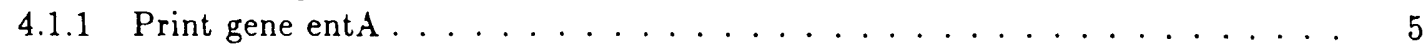

4.2 Locate Clockwise or Counterclockwise Genes . . . . . . . . . . . . . . . 5

4.2.1 Print all clockwise genes in the genome ............... 5

4.2.2 Print all clockwise genes in the region from 5 minutes to 10 minutes . . . . 6

4.3 Locate Genes Contained in Other Objects on the Chromosome . . . . . . . 6

4.3.1 Print all genes that are contained in kohara clone [101] $9 \mathrm{E} 4 \ldots \ldots$

4.4 Locate Genes by Region or Landmark . . . . . . . . . . . . . . . . . . . . . . 7

4.4.1 Print the gene containing the region from 2396 to $2496 \ldots \ldots$. . . . . . . 7

4.4.2 Print the gene which contains point 20901 . . . . . . . . . . . . 7

4.5 Locate Genes Satisfying Multiple Criteria . . . . . . . . . . . . . . . . . . 7

4.5.1 Print all clockwise genes in the region from $2 \mathrm{~kb}$ to $210 \mathrm{~kb} \ldots \ldots$. . . . . .

4.5.2 Print all translated clockwise genes in the region from oriC to oriC $+8 \mathrm{~kb}$. 7

4.6 Locate Genes Containing Specific Nucleotide Patterns . . . . . . . . . . 8

4.6.1 Let GATCGATC_Genes be all genes that contain the pattern GATCGATC . 8

4.6.2 Print the lengths of GATCGATC_Genes . . . . . . . . . . . . . . . 8

4.7 Display K-mer Usage of Genes . . . . . . . . . . . . . . . . . . . . . . . . 8

4.7.1 Print the 1-mer decomposition of GATCGATC_Genes . . . . . . . . . . 8

4.7.2 Print the 1-mer decomposition of GATCGATC_Genes as 1-mer usage . . . . 8

4.7.3 Print the 2-mer decomposition of GATCGATC_Genes as 2-mer usage . . . . 9

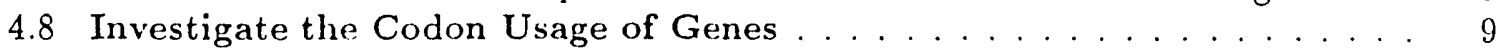

4.8.1 Display Codon Usage of Genes . . . . . . . . . . . . . . . . . 9

4.8.1.1 Print the codon usage of gene entA . . . . . . . . . . . . . 99

4.8.1.2 Print the codon usage of gene ent $\mathrm{A}$ as codon info . . . . . . . . 10

4.8.1.3 Print the codon usage of gene ent A as codon usage . . . . . . . 10 
4.8.2 Assess Distribution of Colons . . . . . . . . . . . . . . . . . . . . . . . 10

4.8.2.1 Let ent. A.Codons be the codon usage of gene ent A . . . . . . . . 10

4.8.2.2 Let entA_Frac be ent.A_Codons / sum of ent A_Codons . . . . . . . . 11

4.8.2.3 Print entA_Frac .................... 11

4.8.2.4 Let AllCodons be codon usage of all translated genes . . . . . . . 11

4.8.2.5 Let AllFrac be AllC odons / sum of AllCodons . . . . . . . . . . . 11

4.8.2.6 Print Allfrac as codon info . . . . . . . . . . . . . . . . . 12

4.8.2.7 Plot AllFrac . . . . . . . . . . . . . . . . . . . . 12

5 Retrieving Information on Sequence Fragments 15

5.1 Print the sequence fragment that contains point oriC . . . . . . . . . . . . . . . 15

5.2 Print all sequence fragments that are in the region from $700 \mathrm{~kb}$ to $760 \mathrm{~kb}$. . . . 15

5.3 Print all restriction fragments for enzyme EcoR5 that are in ampDecoM . . . . . . 15

6 Retrieving Information on Restriction Fragments and Restriction Sites 15

6.1 Print all restriction fragments for enzymes $\{$ Pst 1, EcoR1\} in gene dnal . . . . . . 15

6.2 Print all restriction fragments for enzymes $\{$ Pst1, EcoR1, EcoR5\} in the region from the start of gene ileS $-5 \mathrm{~kb}$ to the start of gene ileS . . . . . . . . . . . . . . 16

6.3 Print all restriction sites for enzyme Aat2 in the genome . . . . . . . . . . . . . 16

7 Investigating Regions on the Chromosome $\quad 16$

7.1 Locate Gaps between Objects . . . . . . . . . . . . . . . . . . . . . . . . . . . . 10

7.1.1 Print the gap between kohara clone [101]9E4 and gene aceE . . . . . . . . 16

7.1 .2 Print the gap between point 7272 and kohara clone $[122] 6 \mathrm{~F} 5 \ldots \ldots 17$

7.1.3 Let GATC_Gaps be the gaps between the occurrences of the pattern GATC . 17

7.2 Compute Gap Length Statistics . . . . . . . . . . . . . . . . . . . . . . . . . . . 17

7.2.1 Let GATC_GapsLength be the length of GATC_Gaps . . . . . . . . . . . . . 17

7.2 .2 Print the mean of GATC_GapsLength . . . . . . . . . . . . . . . . . . 17

7.2 .3 Print the max of GATC_GapsLength . . . . . . . . . . . . . . . . . . . 17

7.2.4 Let RealGaps be GATC_Gaps that are sequenced . . . . . . . . . . . . . . 17

7.2 .5 Let RealGapsLength be the length of RealGaps . . . . . . . . . . . . . . . . . 18

7.2 .6 Print the mean of RealGapsLength . . . . . . . . . . . . . . . . . . . . . . 18

7.3 Specify Regions In Terms of Minutes or Kilobases . . . . . . . . . . . . . . . . . . . . 18

7.3.1 Let SpecialRegion be the region from 34 minutes to 48 minutes . . . . . . . . 18

7.4 Let SpecialRegion be the region from oriC to oriC $+600 \mathbf{k b}$. . . . . . . 18

7.5 Specify Contiguous Pieces of Genome in Terms of Percent Sequenced . . . 18

7.5.1 Let TinyPieces be ( $2 \mathrm{~kb}$ pieces of the genome) that are 76 percent sequenced 18

8 Displaying Sequences of Objects on the Genome 19

8.1 Display Sequence of a Sequenced Object on the Chrsmosome . . . . . . . . 19

8.1.1 Print the sequence of kohara clone [147]2H5 . . . . . . . . . . . . . . . . . 19

8.1.2 Print the sequence of gene $\operatorname{lsp} A \ldots \ldots \ldots \ldots$

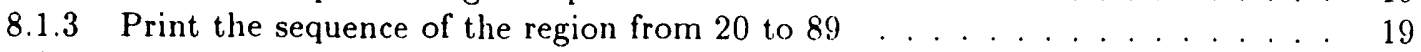

8.2 Display Common Sequences of Given Length . . . . . . . . . . . . . . . . . . . . . . . . 20

8.2.1 Print all sequences of length at least 7 common to \{gene ace $E$, gene ent $A$, gene dnak\} . . . . . . . . . . . . . . . . . 20

8.2.2 Print all sequences of length at least 8 common to \{gene aceE, gene apaC $\quad .20$

8.2.3 Print all sequences of length at least 8 common to \{gene aceE, gene apaG using both strands . . . . . . . . . . . . . . . . . . 20

8.2.4 Print all sequences of length at least 7 common to $\{$ gene ent $A$, gene ace $A$ \} within 0.8 to 1.2 turns apart . . . . . . . . . . . . . . . . . . . . . . . . . 21

8.2.5 Print all sequences of length at least 7 common to \{gene ent $A$, gene acc $A$ \} within 0.8 to 1.2 turns apart using both strands . . . . . . . . . . . 21

8.2.6 Print last_val sorted by length . . . . . . . . . . . . . . . . . . . . . . . 22 
8.3 Display the Proportion Sequenced of a Given Object . . . . . . . . . . 22

8.3.1 Let ClockGenes be all clockwise genes . . . . . . . . . . . . . . . . . 22

8.3.2 For each clockwise gene ClockGenes, \{print ClockGenes; print proportion sequenced of ClockGenes $\} \ldots \ldots . \ldots 22$

8.4 Display Alignment of Sequenced Objects . . . . . . . . . . . . . . . 23

8.4.1 Align (the region from 1548642 to 1548670 , the region from 1799611 to 1799636 ) 23

8.4.2 Align (the region from 0 to 100 , the region from 200 to 300 ) . . . . . . 23

9 Locating Occurrences of Nucleotide Patterns 23

9.1 Locate Occurrences of Standard Nucleotide Patterns . . . . . . . . . . . . 23

9.1.1 Display Explicit Patterns or Their Complements . . . . . . . . . . 23

9.1.1.1 Print the occurrences of pattern GCATC in gene aceE . . . . . . 23

9.1.1.2 Print the occurrences of pattern GCATC' in gene aceE ...... 23

9.1.1.3 Print the occurrences of pattern CCYGG in gene thrC . . . . . 24

9.1.1.4 Print the occurrences of pattern RYRYRYRY in gene aceE . . . . 24

9.1.1.5 Print the occurrences of pattern RYNNRY in gene aceE . . . . . 25

9.1.1.6 Print the occurrences of pattern RYNNRY in gene aceE sorted by sequence . . . . . . . . . . . . . . . 25

9.1.2 Display Hairpin Loops of Any Size . . . . . . . . . . . . 25

9.1.2.1 Print the occurrence of pattern TAG 3..6 TAGT' in the genome . . 25

9.1.2.2 Print the occurrences of pattern $\mathrm{p} 1=\mathrm{RYRY} 3 \ldots 8^{\circ} \mathrm{p} 1$ in gene dnaK. 26

9.1.2.3 Print the occurrences of pattern $\mathrm{p} 1=7 \ldots 73 \ldots 0^{\sim} \mathrm{p} 1$ in the gap between kohara clone $[101] 9 \mathrm{E} 4$ and gene aceE . . . . . . . . 26

9.1.2.4 Print occurrences of the pattern $\mathrm{pl}=4 \ldots 63 \ldots 6^{-} \mathrm{pl}$ in the region from $3400 \mathrm{~kb}$ to $3600 \mathrm{~kb} \ldots \ldots \ldots \ldots 27$

9.1.2.5 Print the occurrences of pattern RYRYRY pl=4..4 $6 \ldots 10$ p $1[1,0,0]$

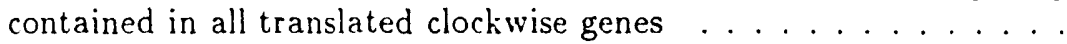

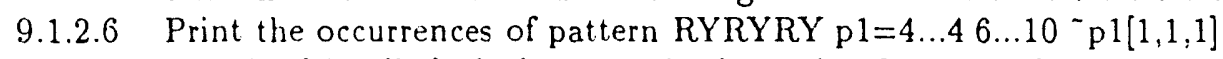
contained in all clockwise genes in the region from 20 minutes to 40

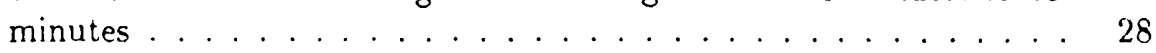

9.1.2.7 Let LargeHairpins be the occurrences of pattern $\mathrm{pl}=10 \ldots 103 \ldots 8$ pl in the region from $200 \mathrm{~kb}$ to $550 \mathrm{~kb}$; print the second punit of LargeHairpins $\} \ldots \ldots \ldots \ldots \ldots \ldots$

9.1.2.8 Print the occurrences of pattern $\mathrm{p} 1=\mathrm{RYYRRY} 2 \ldots 8^{\circ} \mathrm{p} 1$ in the region from $1500 \mathrm{~kb}$ to $2500 \mathrm{~kb} \ldots \ldots \ldots \ldots 29 . \ldots \ldots$

9.1 .2 .9 Print last_val sorted by sequence . . . . . . . . . . . . . . 29

9.1 .2 .10 Print last_val sorted by length . . . . . . . . . . . . . 29

9.1.2.11 Prini tine 1st punit of last_val sorted by sequence . . . . . . . . 30

9.1.2.12 Print the occurrences of pattern $\mathrm{pl}=\mathrm{RYYRRY} 2 \ldots 8^{-\mathrm{p} 1}$ in the region from $1500 \mathrm{~kb}$ to $2500 \mathrm{~kb} \ldots \ldots \ldots \ldots . \ldots \ldots$

9.1.2.13 Print the 3 rd punit of last_val sorted by length . . . . . . . . 31

9.1.2.14 Print the occurrences of pattern $\mathrm{pl}=$ RYYRRY $2 \ldots 8^{-} \mathrm{p} 1$ in the region from $1500 \mathrm{~kb}$ to $2500 \mathrm{~kb}$ sorted by length . . . . . . . . . .

9.1.2.15 Print the occurrences of pattern $\mathrm{pl}=\mathrm{RYYRRY} 2 \ldots 8^{\mathrm{p}} \mathrm{p}$ in the region from $1500 \mathrm{~kb}$ to $2500 \mathrm{~kb}$ sorted by length . . . . . . . . . . 32

9.1.3 Display Embedded Hairpin Loops . . . . . . . . . . . . . . . . . 32

9.1.3.1 Print the occurrences of pattern $\mathrm{p} 1=\mathrm{RYRYY} 2 \ldots 4 \mathrm{p} 2=4 \ldots 63 \ldots 4 \sim \mathrm{p} 2$ $2 \ldots 3$ p 1 in all sequence fragments . . . . . . . . . . 32

9.1.3.2 Print the occurrences of pattern $\mathrm{p} 1=\mathrm{RYRYY} 2 \ldots 4 \mathrm{p} 2=4 \ldots 63 \ldots 4$ p2 $2 \ldots 3 \sim \mathrm{p} 1$ in the region from 30 minutes to 40 minutes . . . . . 33

9.1.3.3 Print the occurrences of pattern $\mathrm{p} 1=\mathrm{RYRYY} 2 \ldots 4 \mathrm{p} 2=4 \ldots 63 \ldots 4-\mathrm{p} 2$ $2 \ldots 3 \mathrm{p} 1$ in the region from $1500 \mathrm{~kb}$ to $2500 \mathrm{~kb}$ sorted by length . . 33

9.1 .3 .4 Print last_val sorted by sequence . . . . . . . . . . . . . . 33

9.1.3.5 Print the 1st punit of last_val sorted by sequence . . . . . . . . 34 
9.1.3.6 Print the occurrences of pattern $\mathrm{pl}=\mathrm{RYRYY} 2 \ldots 4 \mathrm{p} 2=4 \ldots 63 \ldots 4$ $\mathrm{p} 2$ $2 \ldots 3 \sim \mathrm{p} 1$ in the region from $1500 \mathrm{~kb}$ to $2500 \mathrm{~kb}$ sorted by length . . 34

9.1.3.7 Print the 3rd punit of last_val sorted by sequence . . . . . . . . 34

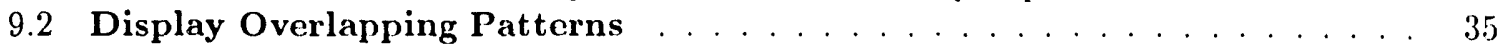

9.2.1 Print all occurrences of pattern $\mathrm{p} 1=2 \ldots 2 \quad 2 \ldots 2$ p1 that overlap with occurrences of pattern ATTGTTA in the region from $4500 \mathrm{~kb}$ to $4700 \mathrm{~kb} \ldots 35$

9.3 Display Occurrences of Nucleotide Patterns in Multiple Objects . . . . . . 35

9.3.1 For each clockwise gene Gene, \{print Gene; print the occurrences of pattern

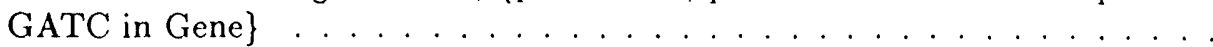

9.3.2 For (each translated counterclockwise gene in the region from $2400 \mathrm{~kb}$ to $2500 \mathrm{~kb}$ ) Gene, \{print Gene; print the occurrences of pattern $\mathrm{p} 1=6 \ldots 610 \ldots 16$

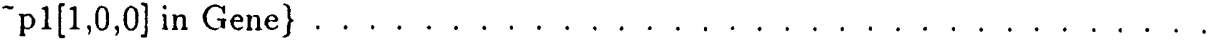

9.3.3 For (each translated counterclockwise gene in the region from $2400 \mathrm{~kb}$ to 2500 $\mathrm{kb})$ Gene, collect the occurrences of pattern $\mathrm{p} 1=6 \ldots 610 \ldots 10^{\mathrm{p}} 1[1,0,0]$ in Gene into Specialloops . . . . . . . . . . . . . . . . . . . . .

9.3.4 For each (gene that contains a member of last_val) Gene, \{Print Gene; print the members of last_val contained in Gene $\} \ldots . . . . . . . . .36$

9.3.5 let GATCGATC_Occs be the occurrences of pattern GATCGATC . . . . . 36

9.3.6 for each (gene that contains a member of GATCGATC_Occs) Gene, \{print Gene; print the members of GATCGATC_Occs contained in Gene\} . . . . . . 37

9.3.7 let GATCGATC_Occs be the occurrences of pattern CiATCGATC; for each (gene that contains a member of GATCGATC_Occs) Gene, \{print Gene; print the members of GATCGATC_Occs contained in Gene $\}$. . . . . . . . . . . . 37

10 Locating Ciosest Occurrences of One Nucleotide Pattern to Another 38

10.1 Let DAM_Occs be the occurrences of pattern GATC in SpecialRegion . . . . . . . . 38

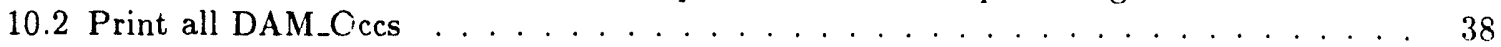

10.3 Let SelectedGenes be translated clockwise genes . . . . . . . . . . . . . . 38

10.4 Print closest occurrences of pattern GATC in SelectedGenes to occurrences of pattern TAG in SelectedGenes . . . . . . . . . . . . . . . . . . . 38

10.5 Print pairs of occurrences of pattern GATC in SelectedGenes and their closest neighboring occurrences of pattern TAG in SelectedGenes . . . . . . . . . . . . . . . 39

10.6 Let TATA_Boxes be occurrences of pattern TATAA . . . . . . . . . . . . . . . 39

10.7 Print the pairs of TATA_Boxes and their closest neighboring genes . . . . . . . . . 39

10.8 Print the pairs of TATA_Boxes and their closest neighboring counterclockwise translated genes . . . . . . . . . . . . . . . . . . 40

10.9 Print the pairs of TATA_Boxes and their closest neighboring counterclockwise translated genes sorted by distance . . . . . . . . . . . . . . . . . . . 40

11 Locating Amino Acid Patterns In Translated Genes 41

11.1 Standard Patterns or Prefixes . . . . . . . . . . . . . . . . . 41

11.1.1 Print occurrences of amino acid pattern C ( ??? | ????) C in translated genes 41

11.2 Zinc Fingers . . . . . . . . . . . . . . . . . . . . 41

11.2.1 Print occurrences of amino acid pattern C (???| ????) C ?????????? (? | (?? | ( ???| ????)) )

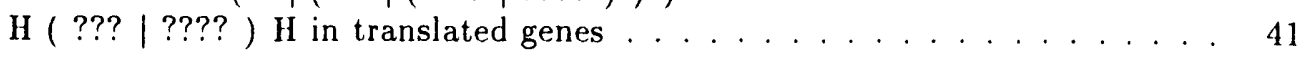

12 Assessing the Distribution of Objects $\quad 42$

12.1 Count the Occurrences of Objects on the Chromosome . . . . . . . . . . 42

12.1.1 Count the occurrences of pattern TGGATGGA in 20-minute pieces of the

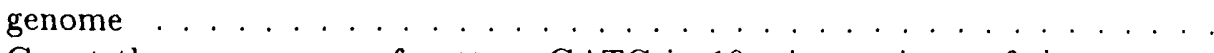

12.1.2 Count the occurrences of pattern GATC in 10-minute pieces of the genome starting at oriC . . . . . . . . . . . . . . . . 42 
12.1.3 Count all restriction fragments for enzymes $\{$ Aat2, EcoR.1 $\}$ in 10 equal parti-

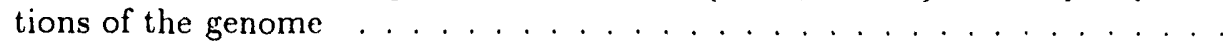

12.1.4 Count the translated counterclockwise genes in (10 equal partitions of the genome starting at oriC) . . . . . . . . . . . . . . . 43

12.1.5 Count the genes in 10 equal partitions of the genome . . . . . . . . . 43

12.1.6 Count the translated genes in $100 \mathrm{~kb}$ pieces of the genome . . . . . . . . 43

12.1.7 Count the clockwise translated genes in 10 equal partitions of the genome . . 44

12.2 Compute the Adjusted Counts of Objects . . . . . . . . . . . . . . . . . . 44

12.2.1 Print the adjusted counts of genes in 10 equal partitions of the genome . . . 44

12.2.2 Print the adjusted counts of translated counterclockwise genes in (10 equal partitions of the genome starting at oriC) . . . . . . . . . 45

12.2.3 Print the adjusted counts of occurrences of pattern CCYGG in 4 equal partitions of the genome starting at oriC . . . . . . . . . . . . 45

13 Defining New Concepts 45

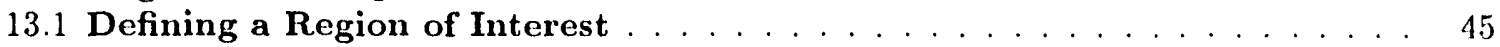

13.1.1 "Define Interesting to be the region from 87 minutes to 88 minutes" . . . . . 45

13.1.2 "Verify the location of region Interesting" . . . . . . . . . . . . . 45

13.1.3 "Find out about genes in region Interesting" . . . . . . . . . . . . . . . 46

13.2 Defining a Name for a Pattern . . . . . . . . . . . . . . . . . . 46

13.2.1 "Define Hair inLoop to be the name of a particular type of hairpin loop" . . 46

13.2.2 "Locate all ciccurrences of hairpin loops of desired type in region Interesting, ordered by lucation" . . . . . . . . . . . . . . . . . . . . . . . 46

13.3 Defining a New Concept in Terms of an Existing Object . . . . . . . . . . 47

13.3.1 "Define Upstream to be the region 100 base pairs upstream of an existing object" 47

13.3.2 "Define Initial to be the first 80 base pairs in an existing object" . . . . . 47

13.3.3 "Use the new concepts Upstream and Initial to investigate each clockwise gene $\mathrm{X}$ in region Interesting" . . . . . . . . . . . . . . . . 47 


\title{
Querving Genomic Databases
}

\author{
by \\ Alexandra Baehr, Ray Hagstrom, David Joerg, and Ross Overbeck
}

\begin{abstract}
A natural-language interface has been developed that retrieves genomic information by using a simple subset of English. The interface spares the biologist from the task of learning databasespecific query languages and computer programming. Currently, the interface deals with the $\mathrm{E}$. coli genome. It can, however, be readily extended and shows promise as a means of easy access to other sequenced genomic databases as well.
\end{abstract}

\section{Introduction}

Molecular biologists investigating the genomes of various species have long been frustrated by the difficulty of accessing the genomic information once it has been entered into databases. To spare biologists the task of learning either database-specific query languages or computer programming, we have built a prototype interface that retrieves genomic information using a simple subset of a familiar natural language - English. Though this natural language interface deals specifically with the E. coli genome, it may be readily extended, and shows promise as a means of easy access to other sequenced genomic databases as well.

Here we present our natural language interface not as a set of formal rules, but as a set of illustrative queries which will suggest many other queries of biological interest. Our rather ambitious future goal is to design a set of semantic primitives flexible enough to express almost any $\mathrm{E}$. coli query a biologist might care to frame. In the meantime, however, our "pidgin" English can retrieve from the integrated $\mathrm{E}$. coli database much useful information that had previously required hours of work, including the reconciliation of diverse notational schemes, to acquire.

Biologists may use this system as it stands, and we plan to add enhancements whenever they find themselves unable to formulate a query into the restricted dialect we support. We also welcome suggestions for other ways of improving the natural language interface. Thus we expect the linguistic model to grow - initially, at least - by accretion. Our hope is that the final linguistic model will be valuable in itself as a framework to support researchers desiring access to wider classes of genomic data.

\section{Locating Reference Points}

\subsection{Origin of Replication}

\subsubsection{Print the point oriC}

query: print the point oric 
2.1.2 Print the point ter A

query: print the point terA

$1348264 / 1348264 \quad 1 \quad$ (point)

\subsection{Establishing Partitions of the Genome}

2.2.1 Print 4 equal partitions of the genome

query: print 4 equal partitions of the genome

\begin{tabular}{|c|c|}
\hline $0 / 1168149$ & (region) \\
\hline $1168150 / 23362991168150$ & (region) \\
\hline $2336300 / 35044491168150$ & (region) \\
\hline $3504450 / 46725991168150$ & (region) \\
\hline
\end{tabular}

2.2.2 Print 4 equal partitions of the genome starting at oriC query: print 4 equal partitions of the genome starting at oriC

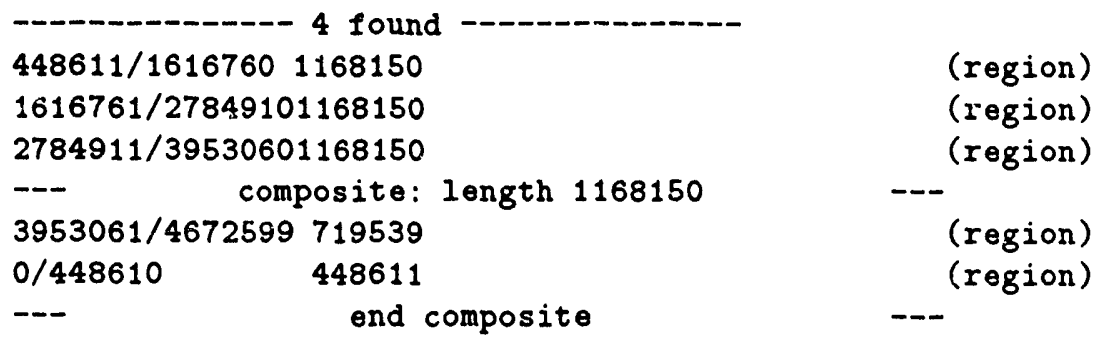

2.2.3 Print 8 equal partitions of the genome starting at 9802 query: print 8 equal partitions of the genome starting at 9802

$\begin{array}{lll}9802 / 593876 & 584075 & \\ 593877 / 1177951 & 584075 & \text { (region) } \\ 1177952 / 1762026 & 584075 & \text { (region) } \\ 1762027 / 2346101 & 584075 & \text { (region) } \\ 2346102 / 2930176 & 584075 & \text { (region) } \\ 2930177 / 3514251 & 584075 & \text { (region) } \\ 3514252 / 4098326 & 584075 & \text { (region) } \\ --\quad \text { composite: length 584075 } & \text { (region) } \\ 4098327 / 4672599 & 574273 & \text { (region) } \\ 0 / 9801 & 9802 & \text { (region) }\end{array}$




\section{Retrieving Information on Kohara Clones}

\subsection{Locate All Kohara Clones}

3.1.1 Print all kohara clones in the genome

query: print all kohara clones in the genome

$\begin{array}{lrcl}0 / 400 & 401 & {[676] 15 A 5(\text { part } 2)} & \text { (Kohara clone) } \\ 383 / 17253 & 16871 & {[101] 9 E 4} & \text { (Kohara clone) } \\ 9400 / 24157 & 14758 & {[102] 6 \mathrm{HB}} & \text { (Kohara clone) } \\ 20930 / 38500 & 17571 & {[103] 22 \mathrm{~B} 12} & \text { (Kohara clone) } \\ 35700 / 53352 & 17653 & {[104] 2 \mathrm{~F} 7} & \text { (Kohara clone) } \\ 39400 / 55700 & 16301 & {[105] 4 \mathrm{A3}} & \text { (Kohara clone) } \\ 51970 / 65027 & 13058 & {[106] 8 \mathrm{D} 2} & \text { (Kohara clone) } \\ 63866 / 80200 & 16335 & {[107] \mathrm{SB5}} & \text { (Kohara clone) } \\ 68512 / 83300 & 14789 & {[108] 8 \mathrm{H} 11} & \text { (Kohara clone) } \\ 79200 / 96783 & 17584 & {[109] 6 \mathrm{C} 1} & \text { (Kohara clone) } \\ 96404 / 118500 & 22097 & {[111] 15 \mathrm{~B} 8} & \text { (Kohara clone) }\end{array}$

3.2 Locate Kohara Clones by Region or Landmark

3.2.1 Print the kohara clones in the region from $400 \mathrm{~kb}$ to $800 \mathrm{~kb}$ query: print the kohara clones in the region from $400 \mathrm{~kb}$ to $800 \mathrm{~kb}$

$\begin{array}{lcr}409727 / 425481 & 15755 & {[143] 6 \mathrm{~A} 12} \\ 416700 / 433300 & 16601 & {[144] 9 \mathrm{GS}} \\ 429100 / 442800 & 13701 & {[145] 4 \mathrm{F3}} \\ 434622 / 452100 & 17479 & {[146] 19 \mathrm{FG}} \\ 446000 / 462911 & 16912 & {[147] 2 \mathrm{H} 5} \\ 459067 / 475300 & 16234 & {[148] 3 \mathrm{~B} 6} \\ 468713 / 484200 & 15488 & {[149] 7 \mathrm{E} 2} \\ 472500 / 492900 & 20401 & {[150] 19 \mathrm{~B} 7} \\ 484200 / 502105 & 17906 & {[151] 8 \mathrm{C} 4} \\ 497700 / 509300 & 11601 & {[152] 12 \mathrm{H} 5} \\ & . & \end{array}$

(Kohara clone)
(Kohara clone)
(Kohara clone)
(Kohara clone)
(Kohara clone)
(Kohara clone)
(Kohara clone)
(Kohara clone)
(Kohara clone)
(Kohara clone)


3.2.2 Print the kohara clones in the region from the start of gene thrC - 5000 to the start of gene thrC

query: print the kohara clones in the region

from the start of gene thrC - 5000 to the start of gene thrC

0/400 401 [676]15A5(part 2) (Kohara -lone)

\subsection{Locate Clones Containing Particular Nucleotide Patterns}

3.3.1 Print all kohara clones that contain the pattern GATC

query: print all kohara clones that contain the pattern GATC

\begin{tabular}{|c|c|c|c|c|}
\hline $383 / 17253$ & 16871 & {$[101] 9 E 4$} & (Kohara & clone) \\
\hline $9400 / 24157$ & 14758 & [102]6 $\mathrm{H3}$ & (Kohara & clone) \\
\hline $20930 / 3850 \mathrm{C}$ & 17571 & {$[103] 22 B 12$} & (Kohara & clone) \\
\hline $35700 / 53352$ & 17653 & {$[104] 2 F 7$} & (Kohara & clone) \\
\hline $39400 / 55700$ & 16301 & {$[105] 4 A 3$} & (Kohara & clone) \\
\hline $51970 / 65027$ & 13058 & {$[106] 8 D 2$} & (Kohara & clone) \\
\hline $63866 / 80200$ & 16335 & {$[107] 5 \mathrm{H} 5$} & (Kohara & clone) \\
\hline $68512 / 83300$ & 14789 & {$[108] 8 \mathrm{H} 11$} & (Kohara & clone) \\
\hline $79200 / 96783$ & 17584 & {$[109] 6 \mathrm{C} 1$} & (Kohara & clone) \\
\hline $96404 / 118500$ & 22097 & {$[111] 15 \mathrm{~B} 8$} & (Kohara & clone) \\
\hline
\end{tabular}

3.3.2 Print all (kohara clones in the region from $400 \mathrm{~kb}$ to $800 \mathrm{~kb}$ ) that contain the pattern GATC

query: print all (kohara clones in the region from $400 \mathrm{~kb}$ to $800 \mathrm{~kb}$ ) that contain the pattern GATC

\begin{tabular}{|c|c|c|c|c|}
\hline $409727 / 425481$ & 15755 & {$[143] 6 A 12$} & (Kohara & clone) \\
\hline $416700 / 433300$ & 16601 & {$[144] 9 G 9$} & (Kohara & clone) \\
\hline $429100 / 442800$ & 13701 & {$[145] 4 F^{3}$} & (Kohara & clone) \\
\hline $434622 / 452100$ & 17479 & {$[146] 19 \mathrm{~F} 6$} & (Kohara & clone) \\
\hline $446000 / 462911$ & 16912 & {$[147] 2 \mathrm{H} 5$} & (Kohara & clone) \\
\hline $459067 / 475300$ & 16234 & {$[148] 3 B 6$} & (Kohara & clone) \\
\hline $468713 / 484200$ & 15488 & {$[149] 7 \mathrm{E} 2$} & (Kohara & clone) \\
\hline $484200 / 502105$ & 17906 & {$[151] 8 \mathrm{C} 4$} & (Kohara & clone) \\
\hline $497700 / 509300$ & 11601 & {$[152] 12 \mathrm{H} 5$} & (Kohara & clone) \\
\hline $504333 / 521000$ & 16668 & {$[153] 4 \mathrm{~B} 10$} & (Kohara & clone) \\
\hline
\end{tabular}


3.3.3 Let SpecialGenes be translated counterclockwise genes that contain the pattern GATCGATC

query: let SpecialGenes be translated counterclockwise genes

that contain the pattern GATCGATC

3.3.4 For each member of SpecialGenes Gene, \{print Gene; print all kohara clones that contain Gene\}

query: for each member of SpecialGenes Gene,

\{print Gene; print all kohara clones that contain Gene\}

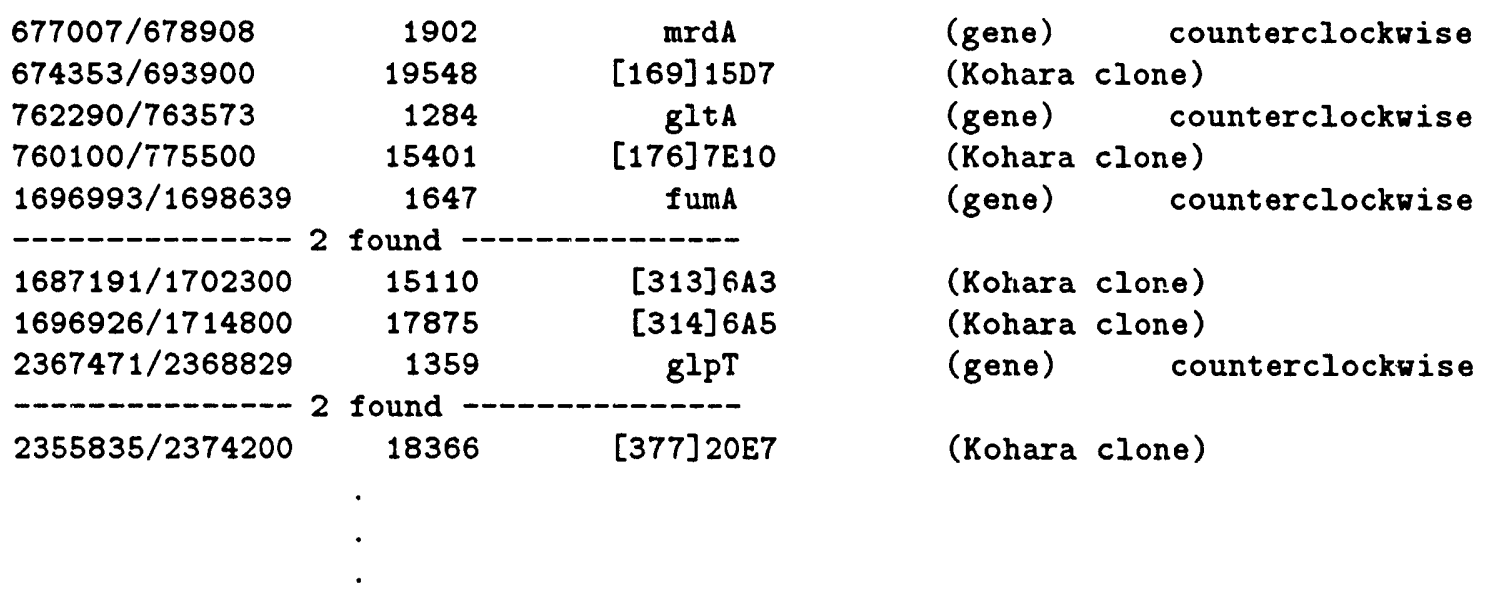

\section{Retrieving Information on Genes}

\subsection{Locate Genes by Id}

4.1.1 Print gene ent $A$

query: print gene entA

$636874 / 637620$

747

ent A

(gene)

clockwise

\subsection{Locate Clockwise or Counterclockwise Genes}

4.2.1 Print all clockwise genes in the genome

query: print all clockwise genes in the genome 


$\begin{array}{lrlll}207 / 2669 & 2463 & \text { found } & \text { (gene) } & \text { clockwise } \\ 2671 / 3600 & 930 & \text { thrB } & \text { (gene) } & \text { clockwise } \\ 3601 / 4887 & 1287 & \text { thrC } & \text { (gene) } & \text { clockwise } \\ 12280 / 14196 & 1917 & \text { dnaK } & \text { (gene) } & \text { clockwise } \\ 14285 / 15415 & 1131 & \text { dnaJ } & \text { (gene) } & \text { clockwise } \\ 15562 / 16836 & 1275 & \text { orf } & \text { (gene) } & \text { clockwise } \\ 17571 / 18659 & 1089 & \text { ant } & \text { (gene) } & \text { clockwise } \\ 18719 / 19507 & 789 & \text { orf } & \text { (gene) } & \text { clockwise } \\ 21425 / 22363 & 939 & \text { orf } & \text { (gene) } & \text { clockwise } \\ 22406 / 23929 & 1524 & \text { iles } & \text { (gene) } & \text { clockwise }\end{array}$

4.2.2 Print all clockwise genes in the region from 5 minutes to 10 minutes query: print all counterclockwise genes in the region from 5 minutes to 10 minutes

13 found

\begin{tabular}{|c|c|c|c|c|}
\hline $243936 / 244012$ & 77 & aspV & $(\operatorname{gen} \theta)$ & counterclockwise \\
\hline $244175 / 244906$ & 732 & dnaq & (gene) & counterclockwise \\
\hline $262253 / 263710$ & 1458 & pepd & (gene) & counterclockwise \\
\hline $266265 / 267320$ & 1056 & phoE & (gene) & counterclockwise \\
\hline $332849 / 334882$ & 2034 & betT & (gene) & counterclockwise \\
\hline $367935 / 368546$ & 612 & IacA & (gene) & counterclockwise \\
\hline $368610 / 369863$ & 1254 & $\operatorname{lac} Y$ & (gene) & counterclockwise \\
\hline $369915 / 372989$ & 3075 & lacz & $(g \in n \theta)$ & counterclockwise \\
\hline $373112 / 374194$ & 1083 & lacI & $(\operatorname{gen} \theta)$ & counterclockwise \\
\hline
\end{tabular}

\subsection{Locate Genes Contained in Other Objects on the Chromosome}

4.3.1 Print all genes that are contained in kohara clone [101]9E4

query: print all genes that are contained in kohara clone [101]9E4

$\begin{array}{lrlll}2671 / 3600 & 930 & \operatorname{thrB} & & \\ 3601 / 4887 & 1287 & \operatorname{thrC} & \text { (gene) } & \text { clockwise } \\ 5550 / 5932 & 383 & \text { orf } & \text { (gene) } & \text { clockwise } \\ 12280 / 14196 & 1917 & \text { dnak } & \text { (gene) } & \text { counterclockwise } \\ 14285 / 15415 & 1131 & \text { dnaJ } & \text { (gene) } & \text { clockwise } \\ 15562 / 16836 & 1275 & \text { orf } & \text { (gene) } & \text { clockwise } \\ 16867 / 17019 & 153 & \text { gef } & \text { (gene) } & \text { counterclockwise }\end{array}$




\subsection{Locate Genes by Region or Landmark}

4.4.1 Print the gene containing the region from 2396 to 2496

query: print the gene containing the region from 2396 to 2496

$207 / 2669$

2463

thra

(gene)

clockwise

4.4.2 Print the gene which contains point 20901

query: print the gene which contains point 20901

$20833 / 21096$

264

rpsT

(gene)

counterclockwise

\subsection{Locate Genes Satisfying Multiple Criteria}

4.5.1 Print all clockwise genes in the region from $2 \mathrm{~kb}$ to $210 \mathrm{~kb}$ query: print all clockwise genes in the region from $2 \mathrm{~kb}$ to $210 \mathrm{~kb}$

$\begin{array}{lrlll}2671 / 3600 & 930 & \text { thrB } & \text { (gene) } & \text { clockwise } \\ 3601 / 4887 & 1287 & \text { thrC } & \text { (gene) } & \text { clockwise } \\ 12280 / 14196 & 1917 & \text { dnaK } & \text { (gene) } & \text { clockwise } \\ 14285 / 15415 & 1131 & \text { dnaJ } & \text { (gene) } & \text { clockwise } \\ 15562 / 16836 & 1275 & \text { orf } & \text { (gene) } & \text { clockwise } \\ 17571 / 18659 & 1089 & \text { ant } & \text { (gene) } & \text { clockwise } \\ 18719 / 19507 & 789 & \text { orf } & \text { (gene) } & \text { clockwise } \\ 21425 / 22363 & 939 & \text { orf } & \text { (gene) } & \text { clockwise } \\ 22406 / 23929 & 1524 & \text { iles } & \text { (gene) } & \text { clockwise } \\ 25142 / 25636 & 495 & \text { lspA } & \text { (gene) } & \text { clockwise }\end{array}$

4.5.2 Print all translated clockwise genes in the region from oriC to oriC $+8 \mathrm{~kb}$ query: print all translated clockwise genes in the region from oric to oric $+8 \mathrm{~kb}$

-0--------- 2 found $3954493 / 3955485$ $3960633 / 3961052$
993

420
asnA

rbsD (gene) clockwise
(gene) clockwise 
4.6 Locate Genes Containing Specific Nucleotide Patterns 4.6.1 Let GATCGATC_Genes be all genes that contain the pattern GATCGATC query: let GATCGATC_Genes be all genes that contain the pattern GATCGATC

4.6.2 Print the lengths of GATCGATC_Genes query: print the lengths of GATCGATC_Genes

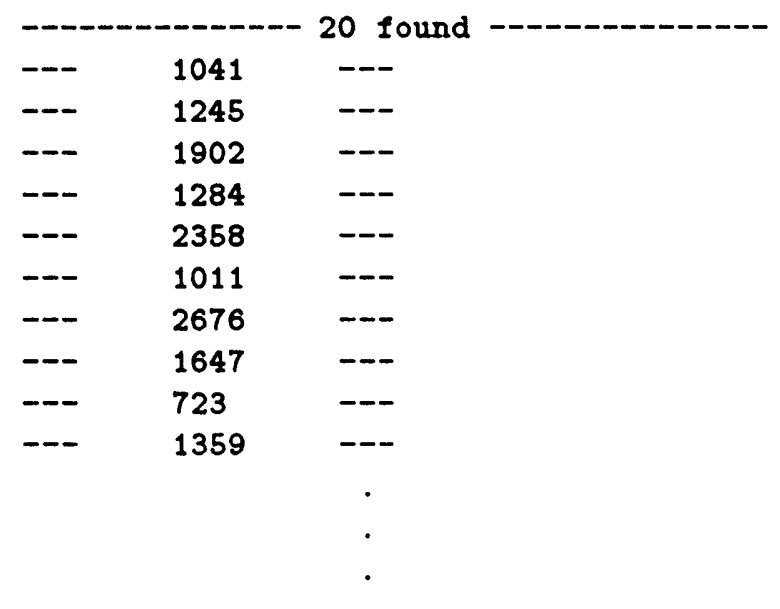

\subsection{Display $\mathrm{K}$-mer Usage of Genes}

4.7.1 Print the 1-mer decomposition of GATCGATC_Genes query: print the 1-mer decomposition of GATCGATC_Genes

$\begin{array}{lcc}--n & \\ -- & 0 & --- \\ -- & 8368 & --- \\ -- & 9375 & --- \\ -- & 9059 & --- \\ -- & 8262 & ---\end{array}$

4.7.2 Print the 1-mer decomposition of GATCGATC_Genes as 1-mer usage query: print the 1-mer decomposition of GATCGATC_Genes as 1-mer usage

invalid 1-mers: 0 found $0.00 \%$ 

A : 8368
$0.24 \%$
C: 9375
$0.27 \%$
G: 9059
$0.26 \%$
$\mathrm{T}: \mathbf{8 2 6 2}$
$0.24 \%$

4.7.3 Print the 2-mer decomposition of GATCGATC_Genes as 2-mer usage query: print the 2-mer decomposition of GATCGATC_Genes as 2-mer usage

\begin{tabular}{|c|c|}
\hline invalid 2mers: 0 & $0.00 \%$ \\
\hline AA : 2313 & $0.07 \%$ \\
\hline AC: 1983 & $0.06 \%$ \\
\hline AG: 1882 & $0.05 \%$ \\
\hline AT: 2183 & $0.06 \%$ \\
\hline CA: 2607 & $0.07 \%$ \\
\hline CC: 2130 & $0.06 \%$ \\
\hline CG: 2967 & $0.08 \%$ \\
\hline CT: 1671 & $0.05 \%$ \\
\hline$G A: 2032$ & $0.06 \%$ \\
\hline
\end{tabular}

\subsection{Investigate the Codon Usage of Genes}

\subsubsection{Display Codon Usage of Genes}

4.8.1.1 Print the codon usage of gene ent $A$

query: print the codon usage of gene entA

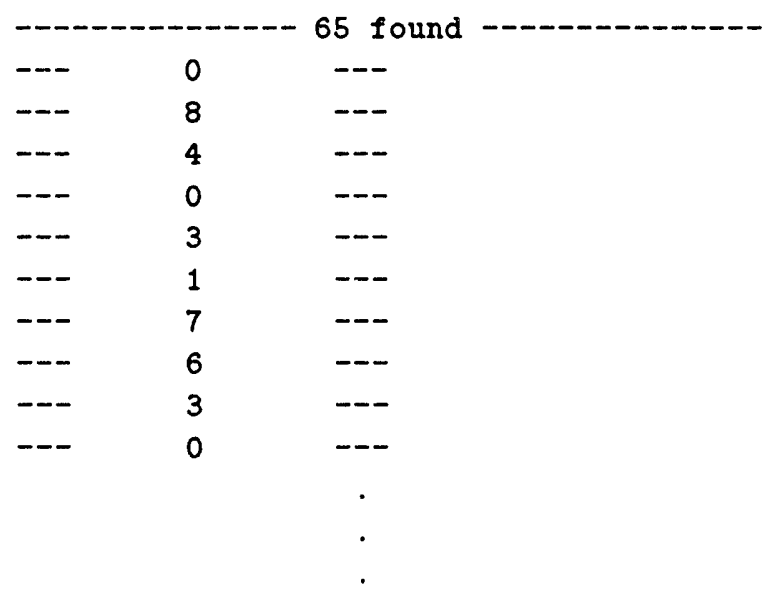


4.8.1.2 Print the codon usage of gene ent $A$ as codon info

query: print the codon usage of gene entA as codon info

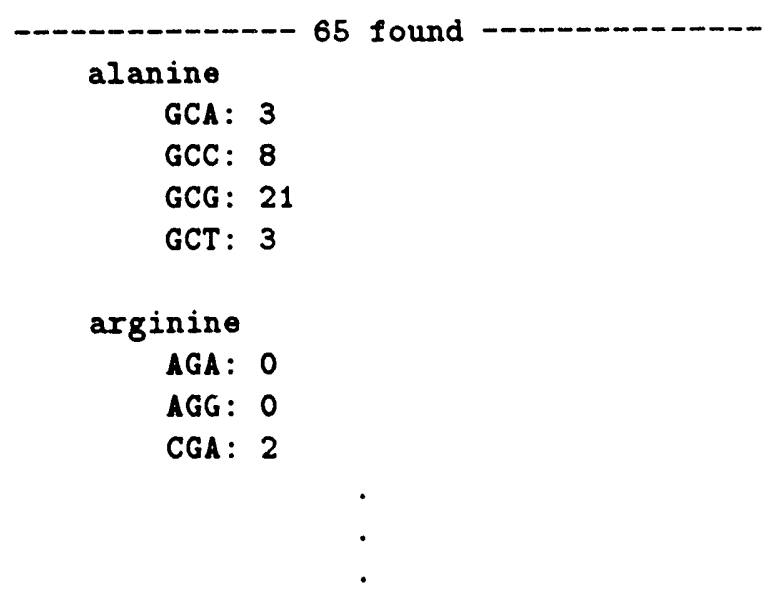

4.8.1.3 Print the codon usage of gene ent $A$ as codon usage

query: print the codon usage of gene entA as codon usage

$\begin{array}{rl}\text { number valid codons }=249 \\ \text { number invalid codons }=0 \\ \text { alanine: } 35 & 14.06 \% \\ \text { GCA : } 3 & 1.20 \% \\ \text { GCC: } 8 & 3.21 \% \\ \text { GCG: } 21 & 8.43 \% \\ \text { GCT: } 3 & 1.20 \% \\ \text { arginine: } 12 & 4.82 \%\end{array}$

\subsubsection{Assess Distribution of Codons}

4.8.2.1 Let ent A_Codons be the codon usage of gene ent $A$

query: let entA_Codons be the codon usage of gene entA 
4.8.2.2 Let ent A_Frac be entA_Codons / sum of entA_Codons

query: let entA_Frac be entA_Codons / sum of entA_Codons

65 found

\subsubsection{Print ent A_Frac}

query: print entA_Frac

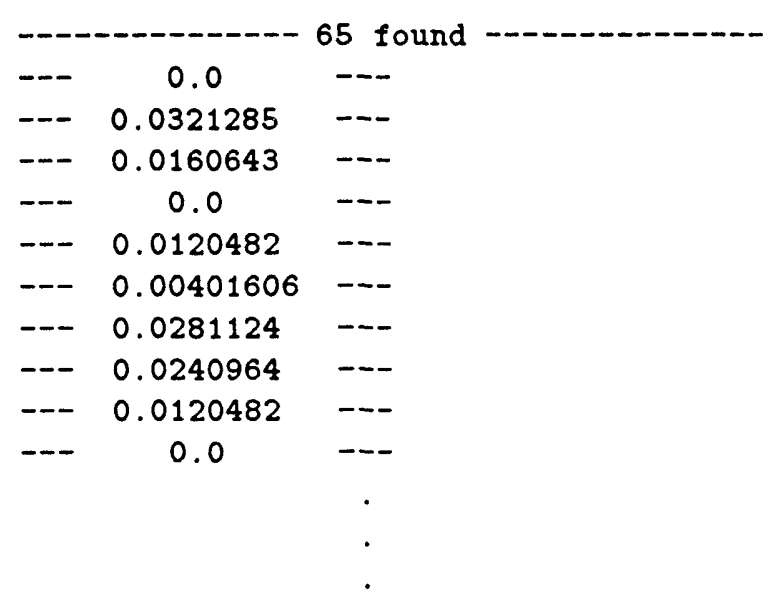

4.8.2.4 Let AllCodons be codon usage of all translated genes

query: let AllCodons be codon usage of all translated genes

65 found

4.8.2.5 Let AllFrac be AllCodons / sum of AllCodons

query: let AllFrac be AllCodons / sum of AllCodons 
4.8.2.6 Print AllFrac as codon info

query: Print AllFrac as codon info

$\begin{aligned} & \text { alanine } 65 \text { found } \\ & \text { GCA }: 0.0201498 \\ & \text { GCC: } 0.0242952 \\ & \text { GCG: } 0.035903 \\ & \text { GCT: } 0.0165187 \\ & \text { arginine } \\ & \text { AGA: } 0.00114233 \\ & \text { AGG: } 8.4399 \theta-04 \\ & \text { CGA }: 0.00279891\end{aligned}$




\subsubsection{Plot AllFrac}
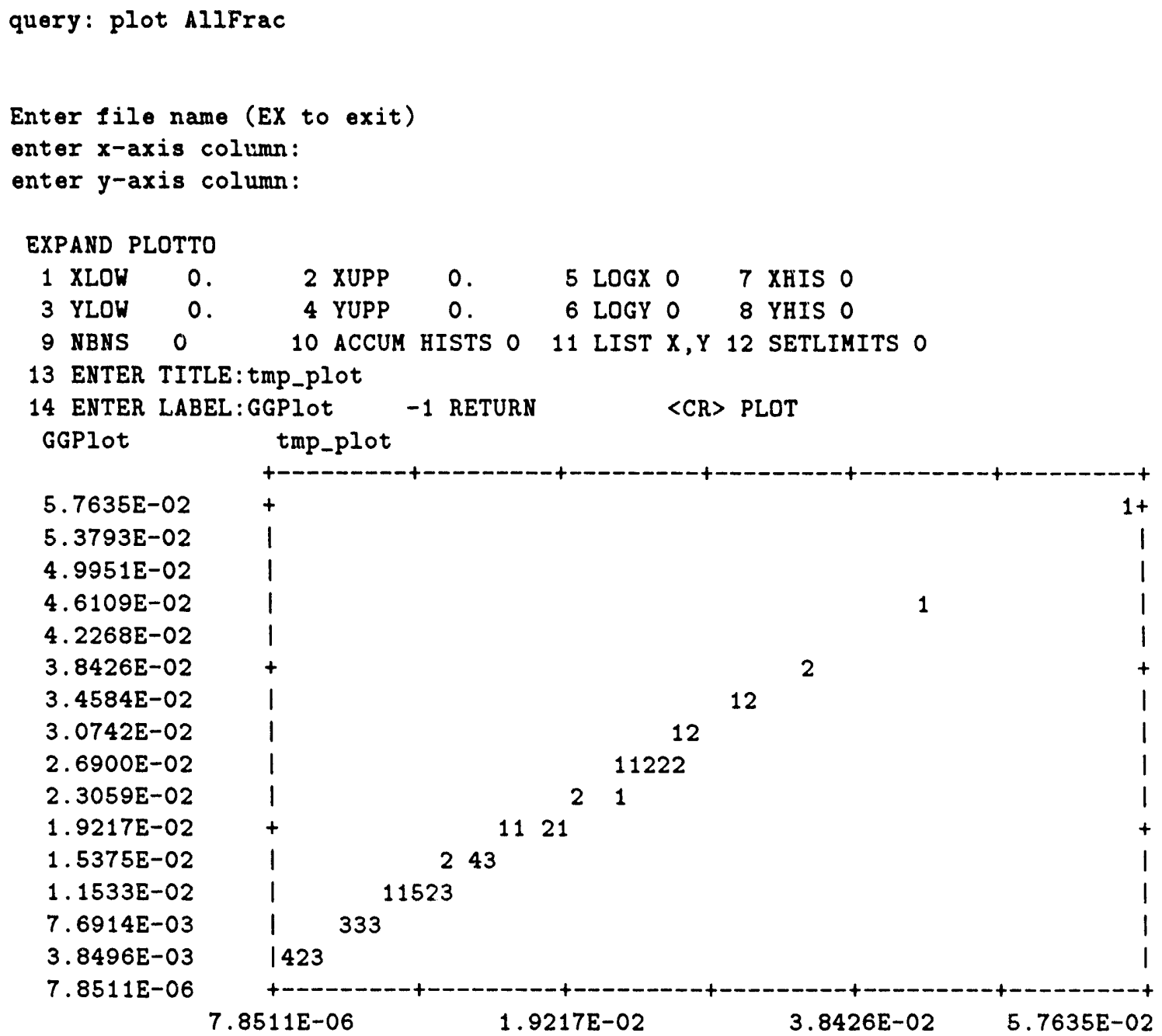

XMN 7.85E-06 XMX 5.76E-02 XPK 5.7SE-02 XVL 7.85E-06 XBR 1.54E-02 XSG $1.16 \mathrm{E}-02$

YMN 7.85E-06 YMX 5.76E-02 YLF 7.85E-06 YRT 5.76E-02 YBR 1.54E-02 YSG $1.16 \mathrm{E}-02$

HBR 2.41E-02 HSG 1.28E-02 SLP 1.00E+00 CEP $0.00 E+00$ COR 1.000000 I/0 $65 / 6$ 
EXPAND PLOTTO

1 XLOW 7.851E-06 2 XUPP 5.763E-02 5 LOGX $0 \quad 7$ XHIS 1

3 YLOW 7.851E-06 4 YUPP 5.763E-02 6 LOGY $0 \quad 8$ YHIS 0

9 IBNS $0 \quad 10$ ACCUM HISTS 011 LIST $X, Y 12$ SETLIMITS 0

13 ENTER TITLE:tmp_plot

14 ENTER LABEL:GGPIot -1 RETURN <CR> PLOT

GGPIot

tmp_plot

$5.0000 \mathrm{E}+00$

4. $6667 \mathrm{E}+00$

4. 3333E+00

4. $0000 \mathrm{E}+00$

$3.6667 \mathrm{E}+00$

3. $3333 \mathrm{E}+00$

3. $0000 \mathrm{E}+00$

2. $6667 \mathrm{E}+00$

2. $3333 \mathrm{E}+00$

2. $0000 \mathrm{E}+00$

1. $6667 \mathrm{E}+00$

1. $3333 \mathrm{E}+00$

1. $0000 \mathrm{E}+00$

6. 6667E-01

3. 3333E-01

$0.0000 E+00$
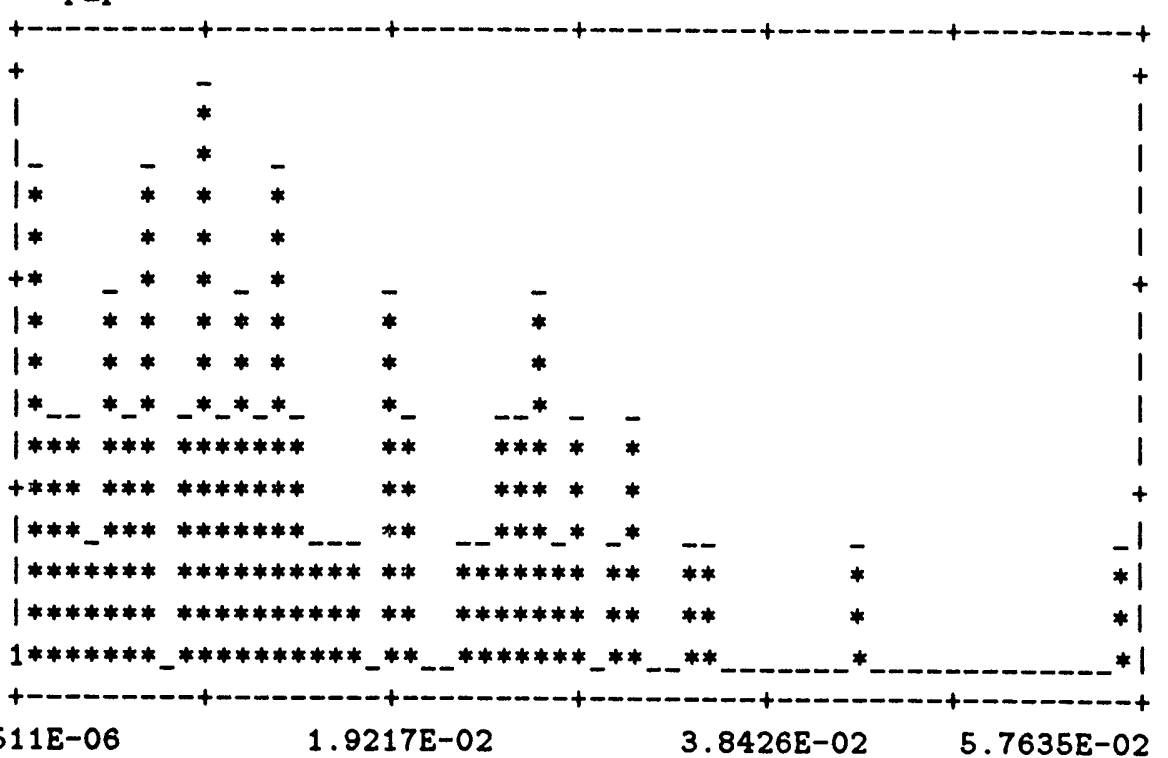

XMH 9.68E-04 XMX 5.76E-02 XPK 9.61E-03 XVL 7.69E-03 XBR 2.93E-02 XSG $1.66 E-02$

YMN $0.00 E+00$ YHX 5.00E+00 YLF 4.00E+00 YRT 1.00E+00 YBR 1.08E+00 YSG $1.28 E+00$ HBR 1.59E-02 HSG 1.16E-02 SLP-5.26E+01 CEP 2.62E+00 COR-0.682099 I/O $60 / \quad 1$ $-1$

Welcome back to the database interface. 


\section{Retrieving Information on Sequence Fragments}

5.1 Print the sequence fragment that contains point oriC

query: print the sequenca fragment which contains point oric

$3929220 / 3956394 \quad 27175$ bglBecoM (DNA fragment)

5.2 Print all sequence fragments that are in the region from $700 \mathrm{~kb}$ to $760 \mathrm{~kb}$

query: print all sequence fragments that are in the region

from $700 \mathrm{~kb}$ to $760 \mathrm{~kb}$

$707654 / 719805$
$732241 / 740153$
$748624 / 750662$

3

$\begin{array}{rr}12152 & \text { glnVecol } \\ 7913 & \text { kdpEecol } \\ 2039 & \text { ECOPHRORF }\end{array}$

(DNA fragment)
(DNA fragment)
(DNA fragment)

5.3 Print all restriction fragments for enzyme EcoR5 that are in ampDecoM query: print all restriction fragments for enzyme EcoR5 that are in ampDecoM

6 Retrieving Information on Restriction Fragments and Restriction Sites

6.1 Print all restriction fragments for enzymes $\{$ Pst1, EcoR1 $\}$ in gene dnaK

query: print all restriction fragments for enzymes \{Pst1, EcoR1\} in gene dnaK 


$\begin{array}{lrll}13007 / 13143 & 137 & {[\text { EcoR1,Pst 1] }} & \text { (computed rest. frag.) } \\ 13144 / 13253 & 110 & \text { [Pst1,Pst1] } & \text { (computed rest. frag.) } \\ 13254 / 13604 & 351 & \text { [Pst1,Pst1] } & \text { (computed rest. frag.) }\end{array}$

6.2 Print all restriction fragments for enzymes $\{$ Pst1, EcoR1, EcoR5 $\}$ in the region from the start of gene ileS - $5 \mathrm{~kb}$ to the start of gene ileS

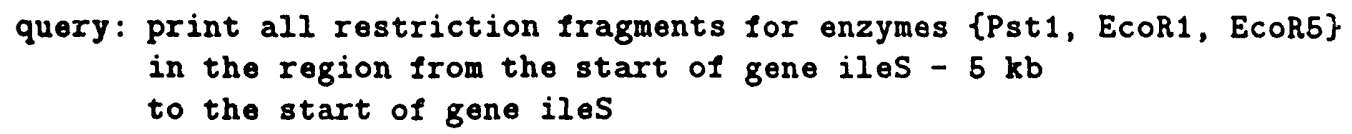

$\begin{array}{lrll}19423 / 20405 & 983 & \text { [Pst1,Pst1] } & \text { (computed rest. Irag.) } \\ 20406 / 21873 & 1468 & \text { [Pst1,EcoR5] } & \text { (computed rest. Irag.) }\end{array}$

6.3 Print all restriction sites for enzyme Aat2 in the genome query: print all restriction sites for enzyme Aat2 in the genome

$\begin{array}{lrll}20222 / 20227 & 6 & \text { Aat2 } & \\ 86869 / 86874 & 6 & \text { Aat2 } & \text { (seq. rest. site) } \\ 88454 / 88459 & 6 & \text { Aat2 } & \text { (seq. rest. site) } \\ 109301 / 109306 & 6 & \text { Aat2 } & \text { (seq. rest. site) } \\ 122553 / 122558 & 6 & \text { Aat2 } & \text { (seq. rest. site) } \\ 127555 / 127560 & 6 & \text { Aat2 } & \text { (seq. rest. site) } \\ 170755 / 170760 & 6 & \text { Aat2 } & \text { (seq. rest. site) } \\ 171543 / 171548 & 6 & \text { Aat2 } & \text { (seq. rest. site) } \\ 181157 / 181162 & 6 & \text { Aat2 } & \text { (seq. rest. site) } \\ 197165 / 197170 & 6 & \text { Aat2 } & \text { (seq. rest. site) }\end{array}$

\section{Investigating Regions on the Chromosome}

\subsection{Locate Gaps between Objects}

7.1.1 Print the gap between kohara clone [101]9E4 and gene aceE query: print the gap between kohara clone [101]9E4 and gene aceE 
7.1.2 Print the gap between point 7272 and kohara clone [122]6F5

query: print the gap between point 7272 and kohara clone [122]6F5

$\begin{array}{lll}7273 / 210469 & 203197 & \text { (gap) }\end{array}$

7.1.3 Let GATC_Gaps be the gaps between the occurrences of the pattern GATC query: let GATC_Gaps be the gaps between the occurrences of the pattern GATC

\subsection{Compute Gap Length Statistics}

7.2.1 Let GATC_GapsLength be the length of GATC_Gaps

query: let GATC_GapsLength be the length of GATC_Gaps

6370 found

7.2.2 Print the mean of GATC_GapsLength

query: print the mean of GATC_GapsLength

$---763.286$

7.2.3 Print the max of GATC_GapsLength

query: print the max of GATC_Gapslength

$--101907 \quad---$

7.2.4 Let RealGaps be GATC_Gaps that are sequenced query: let RealGaps be GATC_Gaps that are sequenced 
7.2.5 Let RealGapsLength be the length of RealGaps query: let RealGapsLength be the length of RealGaps

6094 found

7.2.6 Print the mean of RealGapsLength

query: print the mean of RealgapsLength

$--\quad 213.602$

\subsection{Specify Regions In Terms of Minutes or Kilobases}

7.3.1 Let SpecialRegion be the region from 34 minutes to 48 minutes query: let SpecialRegion be the region from 34 minutes to 48 minutes

1 found

7.4 Let SpecialRegion be the region from oriC to oriC $+600 \mathrm{~kb}$ query: let SpecialRegion be the region from oric to oric $+600 \mathrm{~kb}$

7.5 Specify Contiguous Pieces of Genome in Terms of Percent Sequenced

7.5.1 Let TinyPieces be ( $2 \mathrm{~kb}$ pieces of the genome) that are 76 percent sequenced query: let Tinypieces be ( $2 \mathrm{~kb}$ pieces of the genome)

that are 76 percent sequenced 


\section{Displaying Sequences of Objects on the Genome}

\subsection{Display Sequence of a Sequenced Object on the Chromosome}

8.1.1 Print the sequence of kohara clone [147]2H5

query: print the sequence of kohara elone [147]2H5

$446000 / 462911$
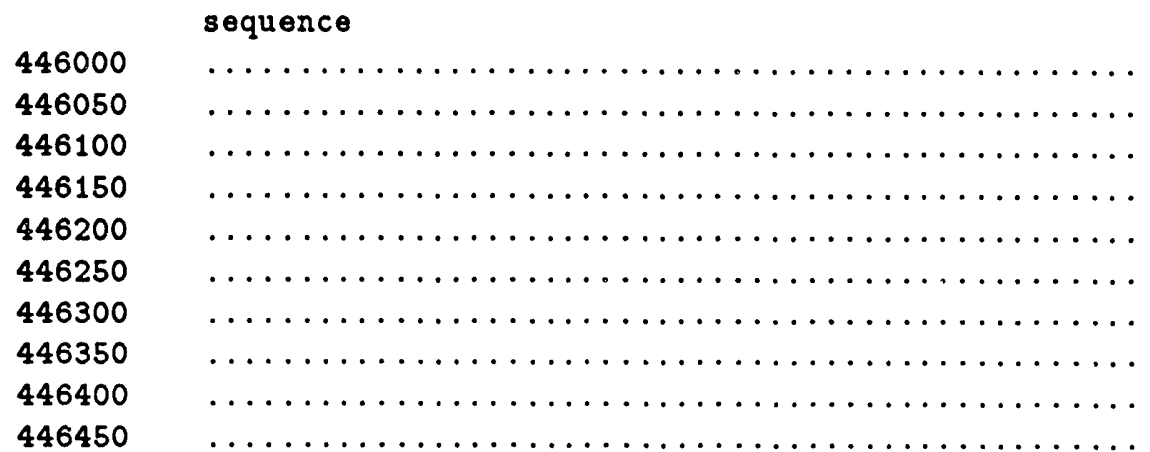

8.1.2 Print the sequence of gene $\operatorname{lsp} A$

query: print the sequence of gene 1spA

$25142 / 25636$ :

sequence
ATGAGTCAATCGATCTGTTCAACAGGGCTACGCTGGCTGTGGCTGGTGGT
AGTCGTGCTGATTATCGATCTGGGCAGCAAATACCTGATCCTCCAGAACT
TTGCTCTGGGGGATACGGTCCCGTGTCCCGTCGTTAATCTGCATTAT
GCGCGTAACTATGGCGCGGCGTTAGTTCCTTGCCGATAGCGGCGGCTG
GCAGCGTTGGTCTTTGCCGTATTGCGATTGGTATTAGCGTGATCCTGG
CAGTGATGATGTATCGCTCGAAGGCCACGCAGAAGCTAAACAATATCGCT
TACGCGCTGATTATTGGCGGCGCCTGGGCAACCTGTTCGACCGCCTGTG
GCACGGCTTCGTTGTCGATATGATCGACTTCTACGTCGGCGACTGGCACT
TCGCCACCTTCAACCTTGCCGATACTGCCATCTGTGTCGGTGCGGCACTG
ATTGTGCTGGAAGGTTTTTGCCTTCTAGAGCGAAAAAACAATAA

8.1.3 Print the sequence of the region from 20 to 89 query: print the sequence of the region from 20 to 89

20/89: sequence AGCGCACAGACAGATAAAATTACAGAGTACACAACATCC^ TGAAACGCA

70 TTAGCACCACCATTACCACC 


\subsection{Display Common Sequences of Given Length}

8.2.1 Print all sequences of length at least 7 common to \{gene aceE, gene ent $A$, gene dnaK\}

query: print all sequences of length at least 7 common

to \{gene aceE, gene entA, gene dnak\}.

\begin{tabular}{|c|c|c|}
\hline 12283/12289: & & sequence \\
\hline & 12283 & GGTAAAA \\
\hline 124547/124553: & & sequence \\
\hline & 124547 & GGTAAAA \\
\hline 636886/636892: & & sequence \\
\hline & 636886 & GGTAAAA \\
\hline 12304/12310: & & sequence \\
\hline & 12304 & CTGGGTA \\
\hline 13474/13480: & & sequence \\
\hline
\end{tabular}

8.2.2 Print all sequences of length at least 8 common to \{gene aceE, gene apaG

query: print all sequences of length at least 8 common to \{gene aceE, gene apaG\}

\begin{tabular}{|c|c|c|}
\hline \multicolumn{3}{|c|}{ 51680/51688: } \\
\hline & 51680 & GAACGGCGA \\
\hline 125242/125250: & & sequence \\
\hline & 125242 & GAACGGCGA \\
\hline 51708/51716: & & sequence \\
\hline & 51708 & GATGCTGAA \\
\hline 24855/124863: & & sequence \\
\hline & 124855 & GATGCTGAA \\
\hline
\end{tabular}

8.2.3 Print all sequences of length at least 8 common to \{gene aceE, gene apaG using both strands

query: print all sequences of length at least 8 common

to \{gene aceE, gene apaG\} using both strands 


\begin{tabular}{|c|c|c|}
\hline \multirow{2}{*}{$51680 / 51688$ : } & & sequence \\
\hline & 51680 & GAACGGCGA \\
\hline \multirow{2}{*}{$125242 / 125250:$} & & sequence \\
\hline & 125242 & GAACGGCGA \\
\hline \multirow[t]{2}{*}{ 51693/51700: } & & sequence \\
\hline & 51693 & GAATACGG \\
\hline \multirow[t]{2}{*}{ 123583/123590: } & & sequence \\
\hline & 123583 & CCGTATTC \\
\hline
\end{tabular}

8.2.4 Print all sequences of length at least 7 common to $\{$ gene ent $A$, gene ace $A$ \} within 0.8 to 1.2 turns apart

query: print all sequences of length at least 7 common to \{gene entA, gene aceA\} within 0.8 to 1.2 turns apart

$\begin{array}{cll}637269 / 637275: & \text { sequence } \\ & 637269 & \text { CGCCGCG } \\ 637280 / 637286: & \text { sequence } \\ 637280 & \text { CGCCGCG } \\ 4247654 / 4247660: & \text { sequence } \\ 4247654 & \text { CGCCGCG }\end{array}$

8.2.5 Print all sequences of length at least 7 common to $\{$ gene ent $A$, gene aceA within 0.8 to 1.2 turns apart using both strands

query: print all sequences of length at least 7 common

to $\{$ gene entA, gene aceA\} within 0.8 to 1.2 turns apart using both strands

\begin{tabular}{|c|c|}
\hline 637269/637275: & sequence \\
\hline 637269 & CGCCGCG \\
\hline 637280/637286: & sequence \\
\hline 637280 & CGCCGCG \\
\hline 4247654/4247660: & sequence \\
\hline 4247654 & CGCCGCG \\
\hline $4247132 / 4247138:$ & sequence \\
\hline 4247132 & CGCGGCG \\
\hline $637545 / 637551:$ & sequence \\
\hline
\end{tabular}


8.2.6 Print last_val sorted by length

query: print last_val sorted by length

\begin{tabular}{|c|c|c|}
\hline \multirow{2}{*}{ 637545/637551: } & & sequence \\
\hline & 637545 & CCTCGCC \\
\hline \multirow{2}{*}{$637557 / 637563:$} & & sequence \\
\hline & 637557 & CCTCGCC \\
\hline \multicolumn{2}{|c|}{ 4247604/4247610: } & sequence \\
\hline & 4247604 & GGCGAGG \\
\hline $637269 / 637275:$ & & sequence \\
\hline & 637269 & CGCCGCG \\
\hline $637280 / 637286:$ & & sequence \\
\hline
\end{tabular}

\subsection{Display the Proportion Sequenced of a Given Object}

8.3.1 Let ClockGenes be all clockwise genes

query: let ClockGenes be all clockwise genes

8.3.2 For each clockwise gene ClockGenes, \{print ClockGenes; print proportion sequenced of ClockGenes \}

query: for each clockwise gene ClockGenes,

\{print ClockGenes; print proportion sequenced of ClockGenes \}

$207 / 2669$

2463

thrA

(gene)

clockwise

$--\quad 1.0$

$2671 / 3600$

$--1.0$

$3601 / 4887$

1.0

$12280 / 14196$

-- $\quad 1.0$

$14285 / 15415$

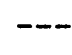

$930 \quad$ thrB

(gene)

clockwise

-- $\quad 1.0$

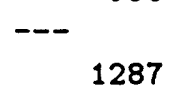

thrC

(gene)

clockwise

1917

dnak

(gene)

clockwise

dnaJ

(gene)

clockwise 
8.4 Display Alignment of Sequenced Objects

8.4.1 Align (the region from 1548642 to 1548670 , the region from 1799611 to 1799636 )

query: align (the region from 1548642 to 1548670 ,

the region from 1799611 to 1799636)

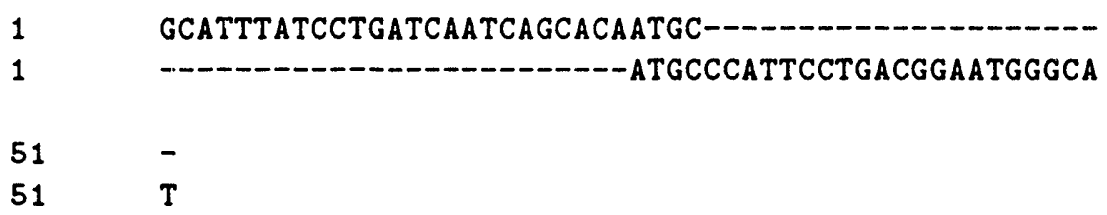

8.4.2 Align (the region from 0 to 100 , the region from 200 to 300 )

query: align (the region from 0 to 100 , the region from 200 to 300 )

Sorry, I can only align completely sequenced objects.

sorry, unable to answer that query

\section{Locating Occurrences of Nucleotide Patterns}

\subsection{Locate Occurrences of Standard Nucleotide Patterns}

9.1.1 Display Explicit Patterns or Their Complements

9.1.1.1 Print the occurrences of pattern GCATC in gene aceE

query: print the occurrences of pattern GCATC in gene aceE

$\begin{array}{lll}124182 / 124186: & 2 \text { found } & \\ 124182 & \begin{array}{l}\text { sequence } \\ \text { GCATC } \\ \text { sequence } \\ \text { 125738/125742: }\end{array} \\ 125738 & \text { GCATC }\end{array}$

9.1.1.2 Print the occurrences of pattern GCATC' in gene aceE

query: print the occurrences of pattern GCATC' in gene aceE 


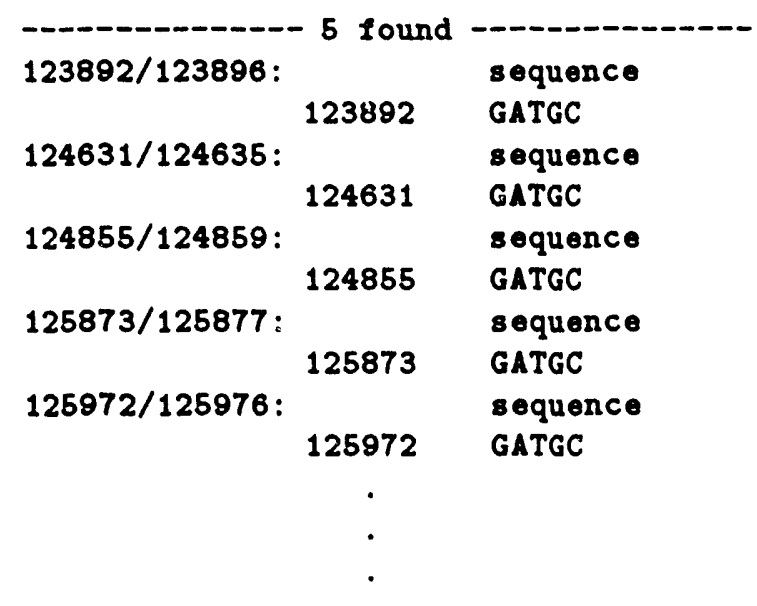

9.1.1.3 Print the occurrences of pattern CCYGG in gene thrC

query: print the occurrences of pattern CCYGG in gene thrC

$\begin{array}{lll}3813 / 3817: & 2 \text { found } & \\ 3813 & \begin{array}{l}\text { sequence } \\ \text { CCTGG } \\ \text { sequence } \\ \text { CCCGG }\end{array}\end{array}$

9.1.1.4 Print the occurrences of pattern RYRYRYRY in gene aceE

query: print the occurrences of pattern RYRYRYRY in gene aceE

$\begin{array}{lll}123628 / 123635: & 11 \text { found } & \\ 123699 / 123706: & \begin{array}{l}\text { sequence } \\ \text { GCGTGCGT }\end{array} \\ 123628 & \begin{array}{l}\text { sequence } \\ \text { ATGTGTGC }\end{array} \\ 123699 & \begin{array}{l}\text { sequence } \\ \text { GTGCACGC } \\ \text { sequence }\end{array} \\ 123723 / 123730: & \begin{array}{l}\text { GCGTGTAC } \\ \text { sequence }\end{array} \\ 123723 / 123790: & \begin{array}{l}\text { sTGTACGC } \\ 123783\end{array}\end{array}$


9.1.1.5 Print the occurrences of pattern RYNNRY in gene aceE

query: print the occurrences of pattern RYNNRY in gene aceE

$\begin{array}{ccc}123368 / 123373: & 165 \text { found } & \begin{array}{l}\text { sequence } \\ \text { GTGGAT }\end{array} \\ 123383 / 123388: & 123368 & \begin{array}{l}\text { sequence } \\ \text { ACTCGC }\end{array} \\ 123390 / 123395: & 123383 & \begin{array}{l}\text { sequence } \\ \text { ACTGGC }\end{array} \\ 123409 / 123414: & 123390 & \begin{array}{l}\text { sequence } \\ \text { ATCGGT }\end{array} \\ 123416 / 123421: & 123409 & \begin{array}{l}\text { sequence } \\ \text { ATCCGT }\end{array} \\ 123416 & \cdot \\ & .\end{array}$

9.1.1.6 Print the occurrences of pattern RYNNRY in gene aceE sorted by sequence

query: print the occurrences of pattern RYNNRY in gene aceE sorted by sequence

$\begin{array}{ccc}124009 / 124014: & 165 \text { found } & \begin{array}{l}\text { sequence } \\ \text { ACAAAC } \\ \text { sequence }\end{array} \\ 125484 / 125489: & 124009 & \begin{array}{l}\text { ACAAAC } \\ \text { sequence }\end{array} \\ 124866 / 124871: & 125484 & \begin{array}{l}\text { ACAAGT } \\ \text { sequence } \\ \text { ACAGGT }\end{array} \\ 123506 / 123511: & 124866 & \begin{array}{l}\text { sequence } \\ \text { ACATGC }\end{array} \\ 125433 / 125438: & 123506 & \\ 125433 & . & \\ & .\end{array}$

9.1.2 Display Hairpin Loops of Any Size

9.1.2.1 Print the occurrence of pattern TAG 3...6 TAGT' in the genome

query: print the occurrence of pattern TAG $3 \ldots 6$ TAGT' in the genome 


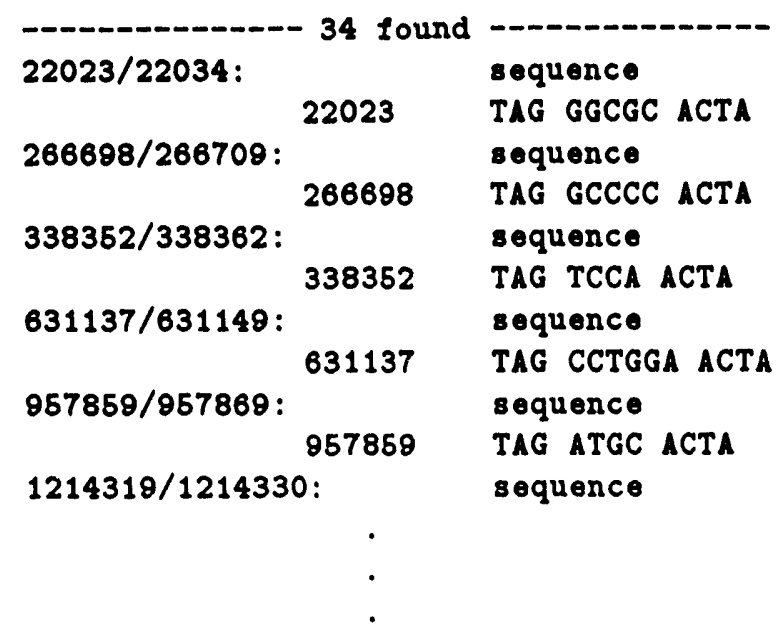

9.1.2.2 Print the occurrences of pattern p1=RYRY $3 . . .8-p 1$ in gene dnaK

query: print the occurrences of pattern $p 1=R Y R Y 3 \ldots 8$ " 1 in gene dnaK

$\begin{array}{lll}12353 / 12368: & 2 \text { found } & \\ 13433 / 13445: & \begin{array}{l}\text { sequence } \\ \text { GCGT GCTGGAGA ACGC } \\ \text { sequence } \\ \text { ACGT AAAA ACGT }\end{array}\end{array}$

9.1.2.3 Print the occurrences of pattern $\mathrm{p} 1=7 \ldots 73 \ldots 6^{-} \mathrm{p} 1$ in the gap between kohara clone $[101] 9 \mathrm{E} 4$ and gene aceE

query: print the occurrences of pattern $p 1=7 \ldots 73 \ldots 6$; 1

in the gap between kohara clone [101]9E4 and gene aceE

\begin{tabular}{|c|c|c|}
\hline $18675 / 18694:$ & & sequence \\
\hline 20992/21010: & 18675 & $\begin{array}{l}\text { GGGAGCC ATAAAC GGCTCCC } \\
\text { sequence }\end{array}$ \\
\hline 24955/24971: & 20992 & $\begin{array}{l}\text { TACTTTC TTGAT GAAAGTA } \\
\text { sequence }\end{array}$ \\
\hline $27191 / 27210:$ & 24 & $\begin{array}{l}\text { CTGCTGA TGC TCAGCAG } \\
\text { sequence }\end{array}$ \\
\hline $5028-2-\gamma$ & 27191 & $\begin{array}{l}\text { TGCCGGT CTTGTT ACCGGCA } \\
\text { sequence }\end{array}$ \\
\hline & 50299 & GGCATGG AAAACG CCATGCC \\
\hline
\end{tabular}


9.1.2.4 Print occurrences of the pattern $\mathrm{p} 1=4 \ldots 63 \ldots 6^{-} \mathrm{p} 1$ in the region from $3400 \mathrm{~kb}$ to $3600 \mathrm{~kb}$

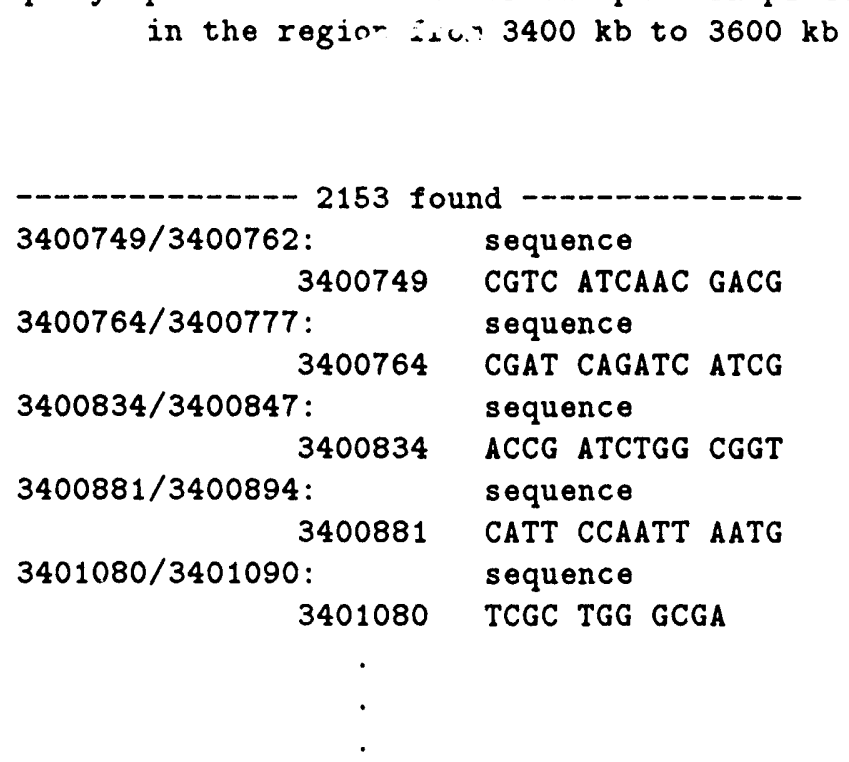

9.1.2.5 Print the occurrences of pattern RYRYRY p1=4..4 6...10 p $1[1,0,0]$ contained in all translated clockwise genes

query: print the occurrences of pattern RYRYRY $p 1=4 \ldots 46 \ldots 10 \sim p 1[1,0,0]$ contained in all translated clockwise genes

\begin{tabular}{|c|c|c|c|}
\hline 260/281: & & sequence & \\
\hline 1558/1581: & 260 & $\begin{array}{l}\text { GCGTGT TGCC } \\
\text { sequence }\end{array}$ & GATATTCT GGAA \\
\hline 1688/1707: & 1558 & $\begin{array}{l}\text { GCGTGC GCGT } \\
\text { sequence }\end{array}$ & TACTCATCAG ATGC \\
\hline $2639 / 2662:$ & 1688 & $\begin{array}{l}\text { ACATAT CGAC } \\
\text { sequence }\end{array}$ & TTACGT GTCT \\
\hline $3498 / 3520:$ & $\begin{array}{l}2639 \\
3498\end{array}$ & $\begin{array}{l}\text { ACGTAC CCTC } \\
\text { sequence } \\
\text { GCGCGT TGCC }\end{array}$ & $\begin{array}{l}\text { TCATGGAAGT TAGG } \\
\text { GACTGGTTG GGTA }\end{array}$ \\
\hline
\end{tabular}


9.1.2.6 Print the occurrences of pattern RYRYRY $p 1=4 \ldots 46 \ldots 10-\mathrm{p} 1[1,1,1]$ contained in all clockwise genes in the region from 20 minutes to 40 minutes

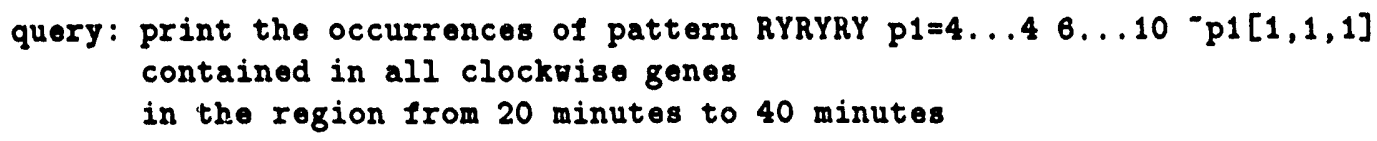

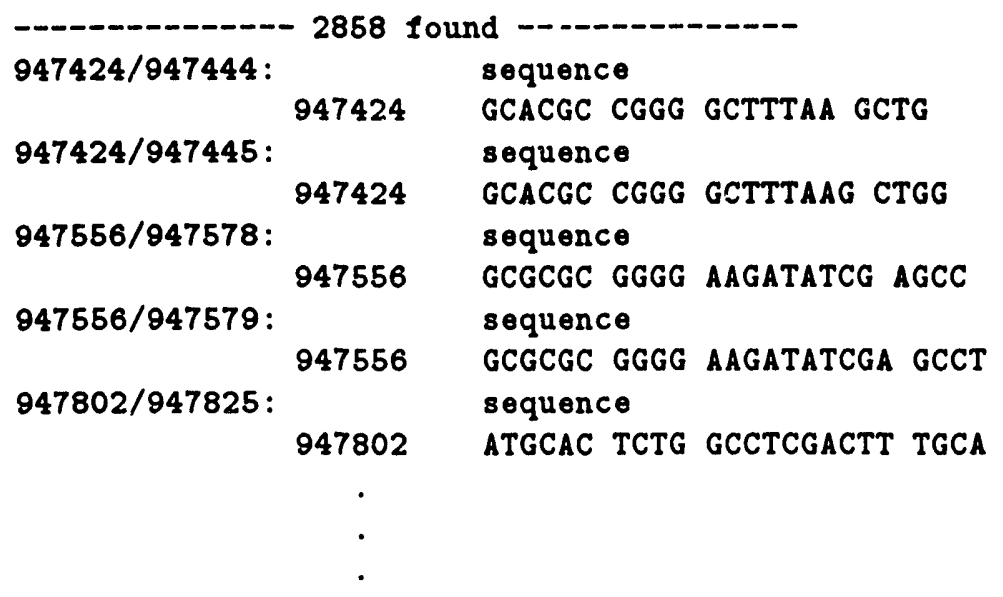

9.1.2.7 Let LargeHairpins be the occurrences of pattern $p 1=10 \ldots 103 \ldots 8 \sim p 1$ in the region from $200 \mathrm{~kb}$ to $550 \mathrm{~kb}$; print the second punit of LargeHairpins\}

query: \{let Largellairpins be the occurrences of pattern $p 1=10 \ldots 103 \ldots 8$ - $p 1$ in the region from $200 \mathrm{~kb}$ to $550 \mathrm{~kb}$; print the second punit of LargeHairpins\}

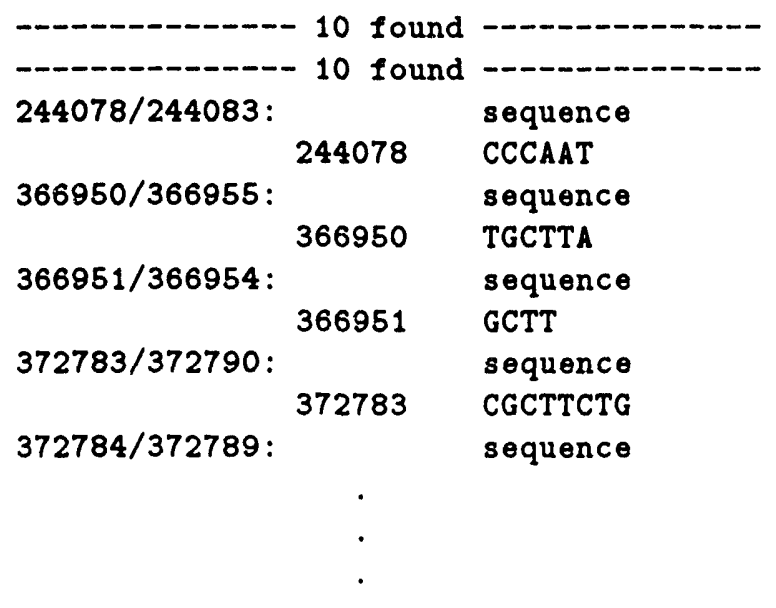


9.1.2.8 Print the occurrences of pattern p1=RYYRRY $2 \ldots 8-p 1$ in the region from $1500 \mathrm{~kb}$ to $2500 \mathrm{~kb}$

query: print the occurrences of pattern p1=RYYRRY $2 \ldots 8$ "p 1

in the region from $1500 \mathrm{~kb}$ to $2500 \mathrm{~kb}$

\begin{tabular}{|c|c|}
\hline 1551760/1551779: & sequence \\
\hline 1551760 & GTTGAC CGAGCAGG GTCAAC \\
\hline 1657772/1657787: & sequence \\
\hline 1657772 & GTTAGT CATA ACTAAC \\
\hline 1659444/1659457: & sequence \\
\hline 1659444 & GTTAAC TG GTTAAC \\
\hline $1807784 / 1807800:$ & sequence \\
\hline 1807784 & ACCAGC GGCAA GCTGGT \\
\hline $1832255 / 1832272:$ & sequence \\
\hline 1832255 & ACCGGC GCAATG GCCGGT \\
\hline
\end{tabular}

9.1.2.9 Print last_val sorted by sequence

query: print last_val sorted by sequence

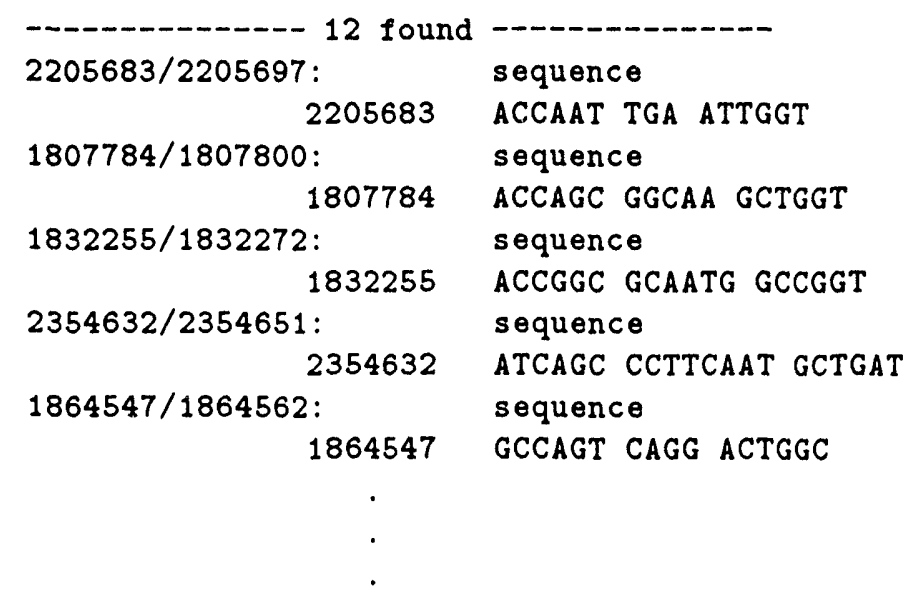

9.1.2.10 Print last_val sorted by length

query: print last_val sorted by length 


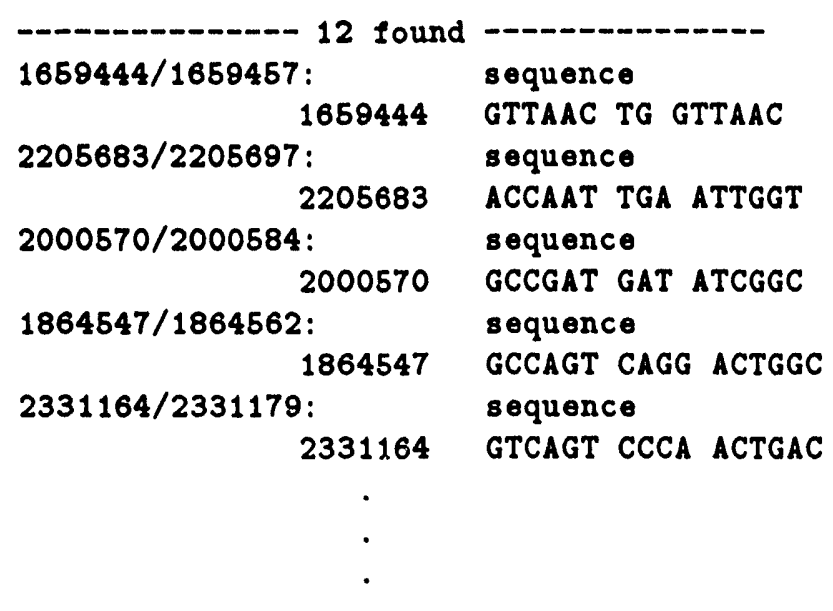

9.1.2.11 Print the 1st punit of last_val sorted by sequence

query: print the 1st punit of last_val sorted by sequence

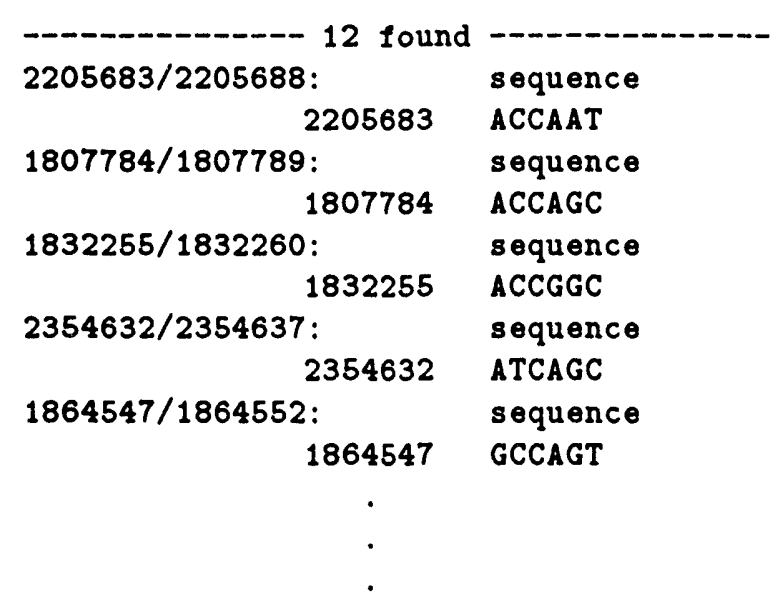

9.1.2.12 Print the occurrences of pattern $p 1=R Y Y R R Y 2 \ldots 8-p 1$ in the region from $1500 \mathrm{~kb}$ to $2500 \mathrm{~kb}$

query: print the occurrences of pattern p1=RYYRRY $2 \ldots 8-p 1$

in the region from $1500 \mathrm{~kb}$ to $2500 \mathrm{~kb}$

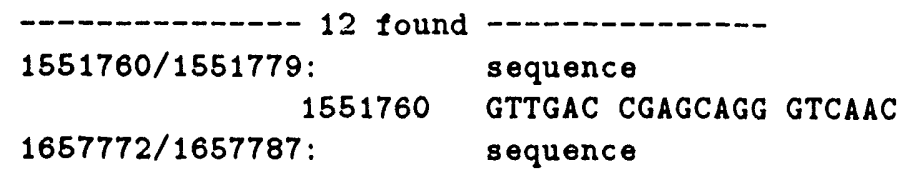




$\begin{array}{cl}1657772 & \text { GTTAGT CATA ACTAAC } \\ 1659444 / 1659457: & \begin{array}{l}\text { sequence } \\ 1659444\end{array} \\ \text { GTTAAC TG GTTAAC } \\ \text { sequence } \\ 1807784 / 1807800: & \text { ACCAGC GGCAA GCTGGT } \\ 1807784 & \text { sequence } \\ 1832255 / 1832272: & \text { ACCGGC GCAATG GCCGGT } \\ 1832255 & \\ \cdot & \\ . & \end{array}$

9.1.2.13 Print the 3rd punit of last_val sorted by length

query: print the 3rd punit of last_val sorted by length

$\begin{array}{cl}1657782 / 1657786: & \text { found } \\ 1657782 & \text { ACTAA } \\ 2331174 / 2331178: & \text { sequence } \\ 2331174 & \text { ACTGA } \\ 1864557 / 1864561: & \text { sequence } \\ 1864557 & \text { ACTGG } \\ 2000579 / 2000583: & \text { sequence } \\ 2000579 & \text { ATCGG } \\ 2205692 / 2205696: & \text { sequence } \\ 2205692 & \text { ATTGG } \\ . & \\ . & \end{array}$

9.1.2.14 Print the occurrences of pattern p1=RYYRRY $2 \ldots 8$ p1 in the region from $1500 \mathrm{~kb}$ to $2500 \mathrm{~kb}$ sorted by length

query: print the occurrences of pattern p1=RYYRRY $2 \ldots 8$ "p 1

in the region from $1500 \mathrm{~kb}$ to $2500 \mathrm{~kb}$ sorted by length

\begin{tabular}{|c|c|}
\hline 1659444/1659457: & $\begin{array}{l}\text { sequence } \\
\text { sequ }\end{array}$ \\
\hline 1659444 & GTTAAC TG GTTAAC \\
\hline 2205683/2205697: & sequence \\
\hline 2205683 & ACCAAT TGA ATTGGT \\
\hline 2000570/2000584: & sequence \\
\hline 2000570 & GCCGAT GAT ATCGGC \\
\hline $1864547 / 1864562:$ & sequence \\
\hline 1864547 & GCCAGT CAGG ACTGGC \\
\hline 2331164/2331179: & sequence \\
\hline
\end{tabular}


9.1.2.15 Print the occurrences of pattern $p 1=R Y Y R R Y 2 \ldots 8-p 1$ in the region from $1500 \mathrm{~kb}$ to $2500 \mathrm{~kb}$ sorted by length

query: print the occurrences of pattern $p 1=R Y Y R R Y 2 \ldots 8$ " $p 1$ in the region from $1500 \mathrm{~kb}$ to $2500 \mathrm{~kb}$ sorted by length

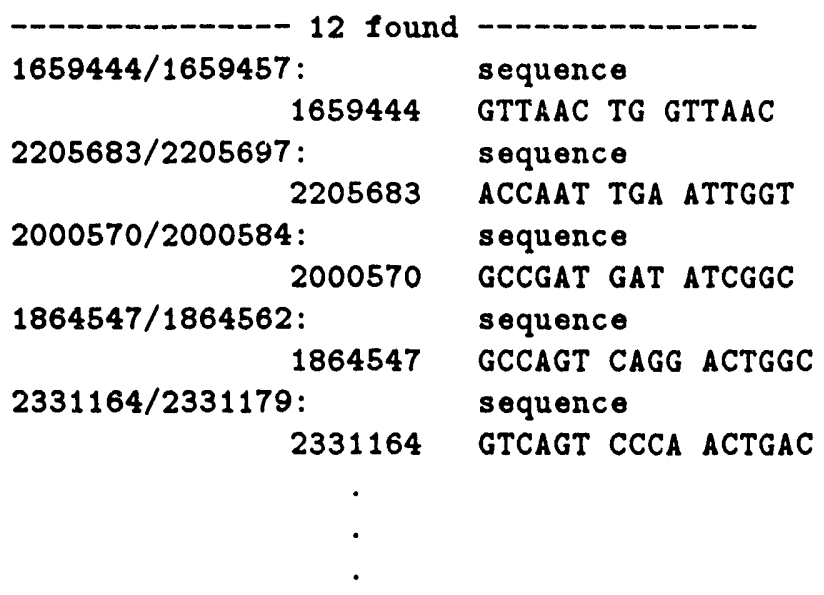

\subsubsection{Display Embedded Hairpin Loops}

9.1.3.1 Print the occurrences of pattern $\mathrm{p} 1=\mathrm{RYRYY} 2 \ldots 4 \mathrm{p} 2=4 \ldots 63 \ldots 4{ }^{\circ} \mathrm{p2} 2 \ldots .3^{-\mathrm{p} 1}$ in all sequence fragments

query: print the occurrences of pattern $\mathrm{p} 1=\mathrm{RYRYY} 2 \ldots 4 \mathrm{p} 2=4 \ldots 63 \ldots 4$

-p2 2...3 ${ }^{-p 1}$ in all sequence fragments

\begin{tabular}{|c|c|}
\hline 203790/203816: & sequence \\
\hline $683941 / 683965:$ & $\begin{array}{l}\text { ATGTT TGG CAAA TTG TTTG GTA AACAT } \\
\text { sequence }\end{array}$ \\
\hline $\begin{array}{l}683941 \\
1548642 / 1548670:\end{array}$ & $\begin{array}{l}\text { GCGCT TT CTGA TTT TCAG TC AGCGC } \\
\text { sequence }\end{array}$ \\
\hline $1799611 / 1799636::^{1548642}$ & $\begin{array}{l}\text { GCATT TATC CTGA TCAA TCAG CAC AATGC } \\
\text { sequence }\end{array}$ \\
\hline $\begin{array}{c}1799611 \\
2368955 / 2368982:\end{array}$ & $\begin{array}{l}\text { ATGCC CA TTCC TGAC GGAA TG GGCAT } \\
\text { sequence }\end{array}$ \\
\hline $\begin{array}{c}2368955 \\
.\end{array}$ & ACATT AT TAAAT AAG ATTTA CAA AATGT \\
\hline
\end{tabular}


9.1.3.2 Print the occurrences of pattern $\mathrm{p} 1=\mathrm{RYRYY} 2 \ldots 4 \mathrm{p} 2=4 \ldots 6 \quad 3 \ldots 4{ }^{-\mathrm{p} 2} 2 \ldots 3-\mathrm{p} 1$ in the region from $\mathbf{3 0}$ minutes to $\mathbf{4 0}$ minutes

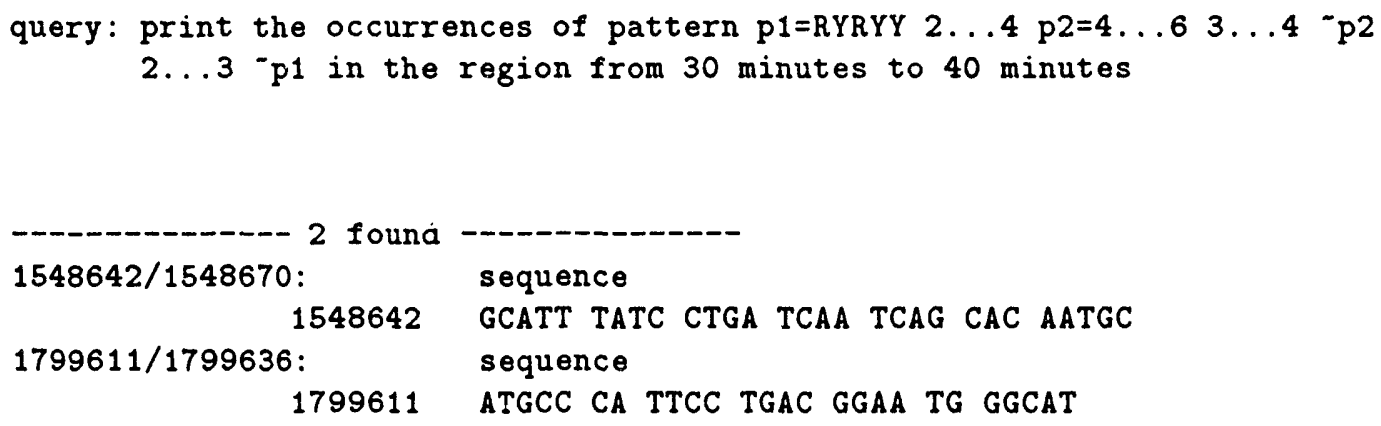

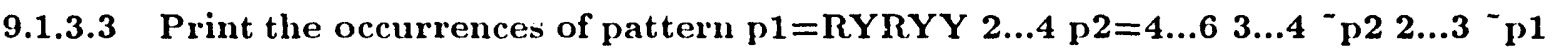
in the region from $1500 \mathrm{~kb}$ to $2500 \mathrm{~kb}$ sorted by length

query: print the occurrences of pattern $p 1=R Y R Y Y 2 \ldots 4 p 2=4 \ldots 63 \ldots 4$ "p2

$2 \ldots 3^{\mathrm{k}} \mathrm{p}$ in the region from $1500 \mathrm{~kb}$ to $2500 \mathrm{~kb}$ sorted by length

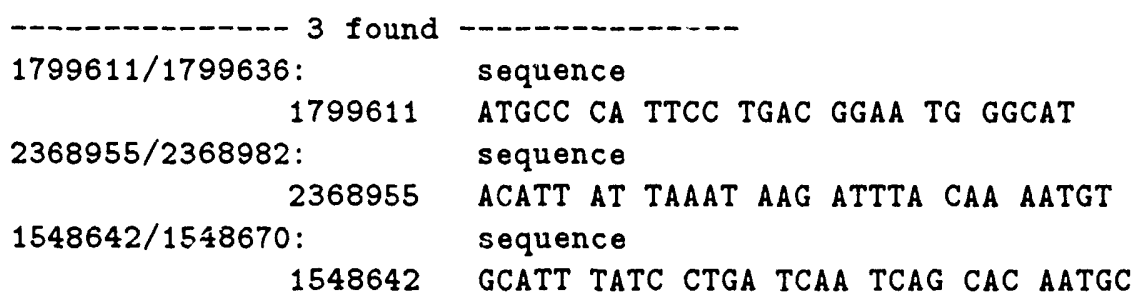

9.1.3.4 Print last_val sorted by sequence

query: print last_val sorted by sequence

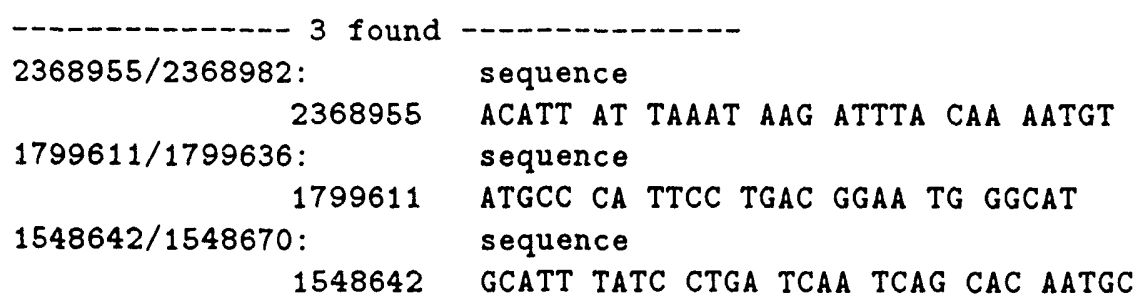


9.1.3.5 Print the 1st punit of last_val sorted by sequence

query: print the 1st punit of last_val sorted by sequence

\begin{tabular}{|c|c|}
\hline $\begin{array}{l}2368955 / 2368959: \\
2368955\end{array}$ & $\begin{array}{l}\text { sequence } \\
\text { ACATT }\end{array}$ \\
\hline 1799611/1799615: & sequence \\
\hline $\begin{array}{c}1799611 \\
1548642 / 1548646:\end{array}$ & $\begin{array}{l}\text { ATGCC } \\
\text { sequence } \\
\text { GCATT }\end{array}$ \\
\hline
\end{tabular}

9.1.3.6 Print the occurrences of pattern $\mathrm{p} 1=\mathrm{RYRYY} 2 \ldots 4 \mathrm{p} 2=4 \ldots 63 \ldots 4-\mathrm{p} 22 \ldots 3$ - 21 in the region from $1500 \mathrm{~kb}$ to $2500 \mathrm{~kb}$ sorted by length

$y=\circ r y:$ print the occurrences of pattern $\mathrm{p} 1=\mathrm{RYRYY} 2 \ldots 4 \mathrm{p} 2=4 \ldots 63 \ldots 4 \mathrm{p} 2$
$2 \ldots 3$ p1 in the region from $1500 \mathrm{~kb}$ to $2500 \mathrm{~kb}$ sorted by length

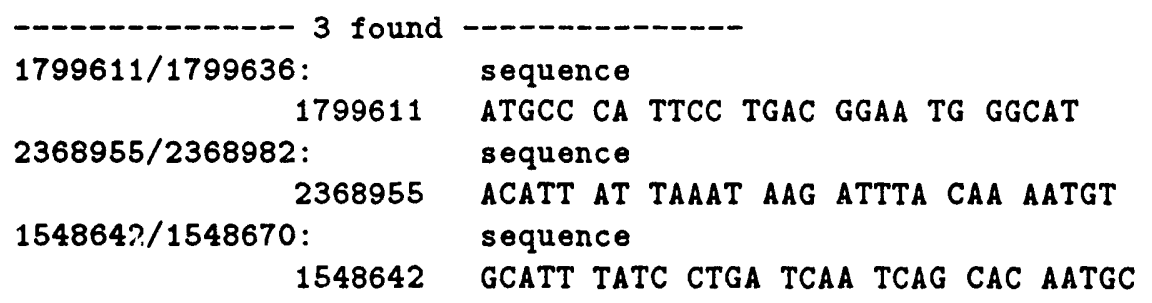

9.1.3.7 Print the 3rd punit of last_val sorted by sequence

query: print the 3rd punit of last_val sorted by sequence

$\begin{array}{cl}1548651 / 1548654: & \text { sequence } \\ 1548651 & \text { CTGA } \\ 2368962 / 2368966: & \text { sequence } \\ 2368962 & \text { TAAAT } \\ 1799618 / 1799621: & \text { sequence } \\ 1799618 & \text { TTCC }\end{array}$




\subsection{Display Overlapping Patterns}

9.2.1 Print all occurrences of pattern $p 1=2 \ldots 2 \quad 2 \ldots 2$ p1 that overlap with occurrences of pattern ATTGTTA in the region from $4500 \mathrm{~kb}$ to $4700 \mathrm{~kb}$

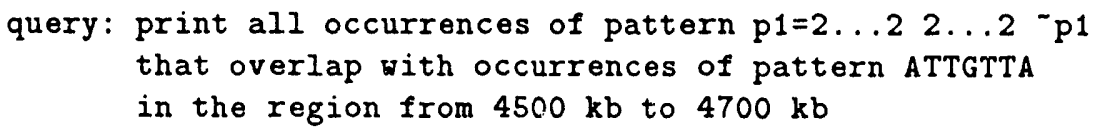

$\begin{array}{cc}4544446 / 4544451: & \text { found } \\ 4544446 & \text { AA AG TT } \\ 4572386 / 4572391: & \text { sequence } \\ 4572386 & \text { AT CT AT } \\ 4608785 / 4608790: & \text { sequence } \\ 4608785 & \text { AA GA TT } \\ 4617703 / 4617708: & \text { sequence } \\ 4617703 & \text { AT TA AT } \\ 4698573 / 4698578: & \text { sequence } \\ 4698573 & \text { TT AG AA } \\ . & \end{array}$

\subsection{Display Occurrences of Nucleotide Patterns in Multiple Objects}

9.3.1 For each clockwise gene Gene, \{print Gene; print the occurrences of pattern GATC in Gene\}

query: for each clockwise gene Gene,

\{print Gene; print the occurrences of pattern GATC in Gene\}

\begin{tabular}{|c|c|c|c|c|}
\hline $207 / 2669$ & & thra & (gene) & clockwise \\
\hline \multicolumn{5}{|c|}{ - 13 found $-\ldots$} \\
\hline \multirow[t]{2}{*}{ 489/492: } & & sequence & & \\
\hline & 489 & GATC & & \\
\hline \multirow[t]{2}{*}{ 596/599: } & & sequence & & \\
\hline & 596 & GATC & & \\
\hline \multirow[t]{2}{*}{$651 / 654:$} & & sequence & & \\
\hline & 651 & GATC & & \\
\hline \multirow[t]{2}{*}{ 750/753: } & & sequence & & \\
\hline & 750 & GATC & & \\
\hline 1037/1040: & & sequence & & \\
\hline
\end{tabular}

9.3.2 For (each translated counterclockwise gene in the region from $2400 \mathrm{~kb}$ to 2500 $\mathrm{kb})$ Gene, \{print Gene; print the occurrences of pattern p1 $=6 \ldots 6 \quad 10 \ldots 16^{-} \mathrm{p} 1[1,0,0]$ in Gene

query: for (each translated counterclockwise gene 
in the region from $2400 \mathrm{~kb}$ to $2500 \mathrm{~kb}$ ) Gene, \{print Gene;

print the occurrences of pattern $p 1=6 \ldots 610 \ldots 16 * p 1[1,0,0]$ in Gene\}

\begin{tabular}{|c|c|c|}
\hline \multirow{2}{*}{$2448124 / 2448693 \quad 570$} & $(\operatorname{gen} \theta)$ & counterclockwise \\
\hline & ------------ & \\
\hline $2448210 / 2448237:$ & sequence & \\
\hline 2448210 & CATCAT CAAGGGATTGCGGGCG ATGATA & \\
\hline $2448211 / 2448236:$ & sequence & \\
\hline 2448211 & ATCATC AAGGGATTGCGGGC GATGAT & \\
\hline $2448212 ; \cdot 448235:$ & sequence & \\
\hline 2448212 & TCATCA AGGGATTGCGGG CGATGA & \\
\hline $2448212 / 2448238:$ & sequence & \\
\hline 2448212 & TCATCA AGGGATTGCGGGCGA TGATAA & \\
\hline $2448223 / 2448248:$ & sequence & \\
\hline
\end{tabular}

9.3.3 For (each translated counterclockwise gene in the region from $2400 \mathrm{~kb}$ ) to 2500 $\mathrm{kb})$ Gene, collect the occurrences of pattern $\mathrm{p} 1=6 \ldots 610 \ldots 16^{-} \mathrm{p} 1[1,0,0]$ in Gene into Specialloops

query: for (each translated counterclockwise gene

in the region from $2400 \mathrm{~kb}$ to $2500 \mathrm{~kb}$ ) Gene,

collect the occurrences of pattern $p 1=6 \ldots 610 \ldots 16 * \mathrm{p} 1[1,0,0]$

in Gene into Specialloops

9.3.4 For each (gene that contains a member of last_val) Gene, \{Print Gene; print the members of last_val contained in Gene

query: for each (gene that contains a member of last_val) Gene, \{print Gene; print the members of last_val contained in Gene\}

$\begin{array}{lllll}2452799 / 2453458 & 660 & \text { dedA } & \text { (gene) } & \text { counterclockwise } \\ 2452799 / 2453458 & 660 & \text { dedA } & \text { (gene) } & \text { counterclockwise }\end{array}$

9.3.5 let GATCGATC_Occs be the occurrences of pattern GATCGATC query: let GATCGATC_Occs be the occurrences of pattern GATCGATC 
9.3.6 for each (gene that contains a member of GATCGATC_Oces) Gene, \{print Gene; print the members of GATCGATC_Oces contained in Gene\}

query: for each (gene that contains a member of GATCGATC_Occs) Gene, \{print Gene; print the members of GATCGATC_Occs contained in Gene\}

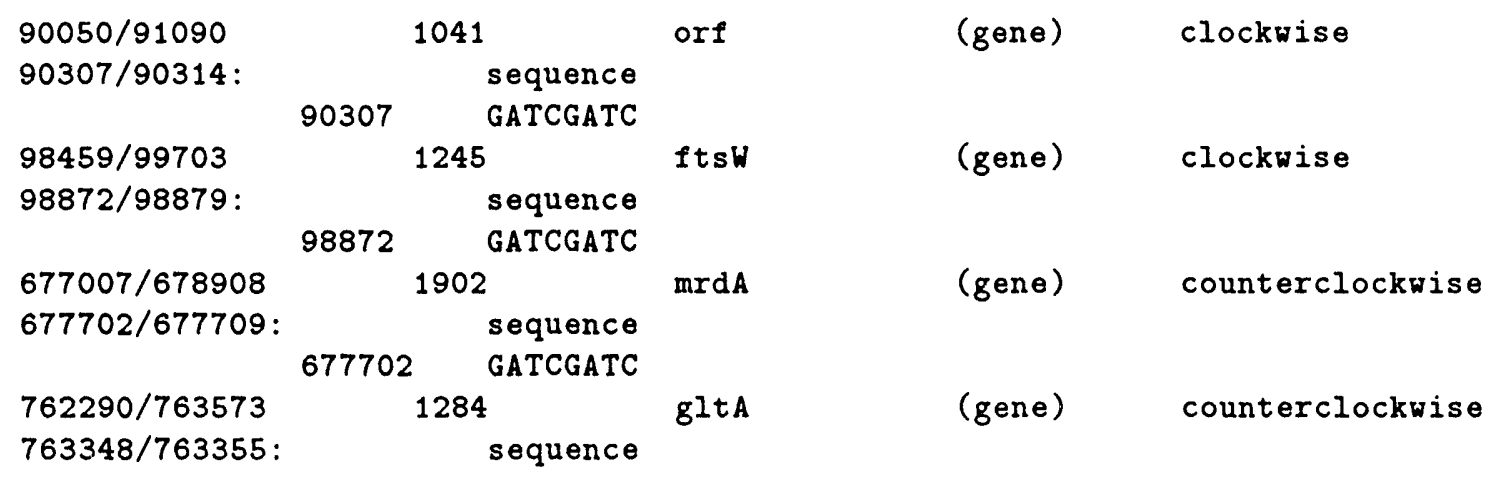

9.3.7 (let GATCGATC_Occs be the occurrences of pattern GATCGATC; for each (gene that contains a member of GATCGATC_Oces) Gene, \{print Gene; print the members of GATCGATC_Occs contained in Gene\})

query: \{let GATCGATC_Dccs be the occurrences of pattern GATCCATC;

for each (gene that contains a member of GATCGATC_Occs) Gene, \{print Gene; print the members of GATCGATC_Occs contained in Gene\}\}

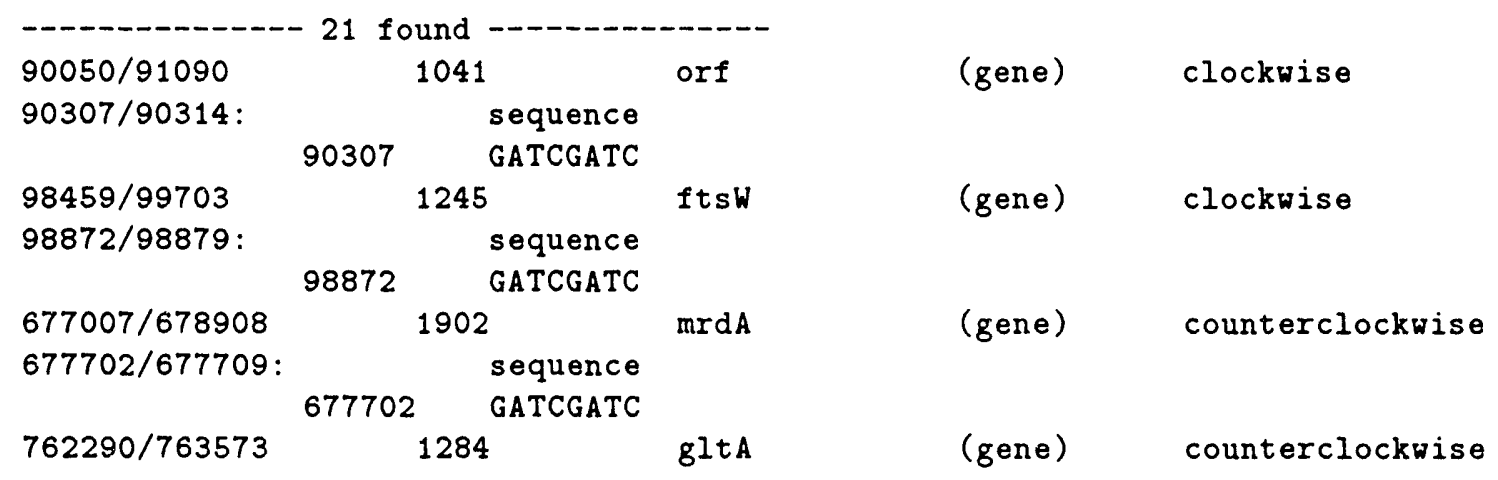




\section{Locating Closest Occurrences of One Nucleotide Pat- tern to Another}

10.1 Let DAM_Occs be the occurrences of pattern GATC in SpecialRegion

query: let DAM_Occs be the occurrences of pattern GATC in SpecialRegion

1074 found

\subsection{Print all DAM_Occs}

query: print all DAM_Occs

$\begin{array}{cl}3953061 / 3953064: & 1074 \text { found } \\ 3953061 & \text { sequence } \\ 3953082 / 3953085: & \text { sequence } \\ 3953082 & \text { GATC } \\ 3953098 / 3953101: & \text { sequence } \\ 3953098 & \text { GATC } \\ 3953113 / 3953116: & \text { sequence } \\ 3953113 & \text { GATC } \\ 3953126 / 3953129: & \text { sequence } \\ 3953126 & \text { GATC } \\ . & \\ . & \end{array}$

10.3 Let SelectedGenes be translated clockwise genes

query: let SelectedGenes be translated clockwise genes

10.4 Print closest occurrences of pattern GATC in SelectedGenes to occurrences of pattern TAG in SelectedGenes

query: print closest occurrences of pattern GATC in SelectedGenes

to occurrences of pattern TAG in SelectedGenes

$\begin{aligned} 489 / 492: & 1706 \text { found } \\ & \text { sequence } \\ & \text { GATC }\end{aligned}$




\begin{tabular}{|c|c|c|}
\hline \multirow{2}{*}{ 596/599: } & & sequence \\
\hline & 596 & GATC \\
\hline \multirow[t]{2}{*}{$651 / 654:$} & & sequence \\
\hline & 651 & GATC \\
\hline \multirow[t]{2}{*}{ 750/753: } & & sequence \\
\hline & 750 & GATC \\
\hline \multirow{2}{*}{ 1037/1040: } & & sequence \\
\hline & 1037 & GATC \\
\hline
\end{tabular}

10.5 Print pairs of occurrences of pattern GATC in SelectedGenes and their closest neighboring occurrences of pattern TAG in SelectedGenes

query: print pairs of occurrences of pattern GATC in SelectedGenes

and their closest neighboring occurrences of pattern TAG in SelectedGenes

\begin{tabular}{|c|c|c|}
\hline--- & \multicolumn{2}{|c|}{ pair: distance 41} \\
\hline $489 / 492:$ & & sequence \\
\hline & 489 & GATC \\
\hline $530 / 532:$ & & sequence \\
\hline & 530 & TAG \\
\hline--- & pa: & tance 23 \\
\hline $596 / 599:$ & & sequence \\
\hline & 596 & GATC \\
\hline $619 / 621:$ & & sequence \\
\hline
\end{tabular}

10.6 Let TATA_Boxes be occurrences of pattern TATAA

query: let TATA_Boxes be occurrences of pattern TATAA

10.7 Print the pairs of TATA_Boxes and their closest neighboring genes query: print the pairs of TATA_Boxes and their closest neighboring genes

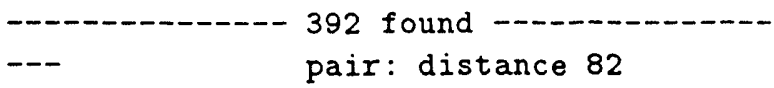




\begin{tabular}{|c|c|c|c|c|}
\hline \multirow{2}{*}{ 14203/14207: } & \multicolumn{2}{|c|}{ sequence } & \multirow[b]{3}{*}{$(g \in n \theta)$} & \multirow[b]{3}{*}{ clockwise } \\
\hline & 14203 & & & \\
\hline $14285 / 15415$ & 1131 & dnaJ & & \\
\hline-- & \multicolumn{2}{|c|}{ pair: distance 354} & \multicolumn{2}{|l|}{---} \\
\hline & 1131 & dnaJ & $(g \in n \theta)$ & clockwise \\
\hline \multirow{2}{*}{$14639 / 14643:$} & \multicolumn{2}{|c|}{ sequence } & & \\
\hline & 14639 & & & \\
\hline
\end{tabular}

10.8 Print the pairs of TATA_Boxes and their closest neighboring counterclockwise translated genes

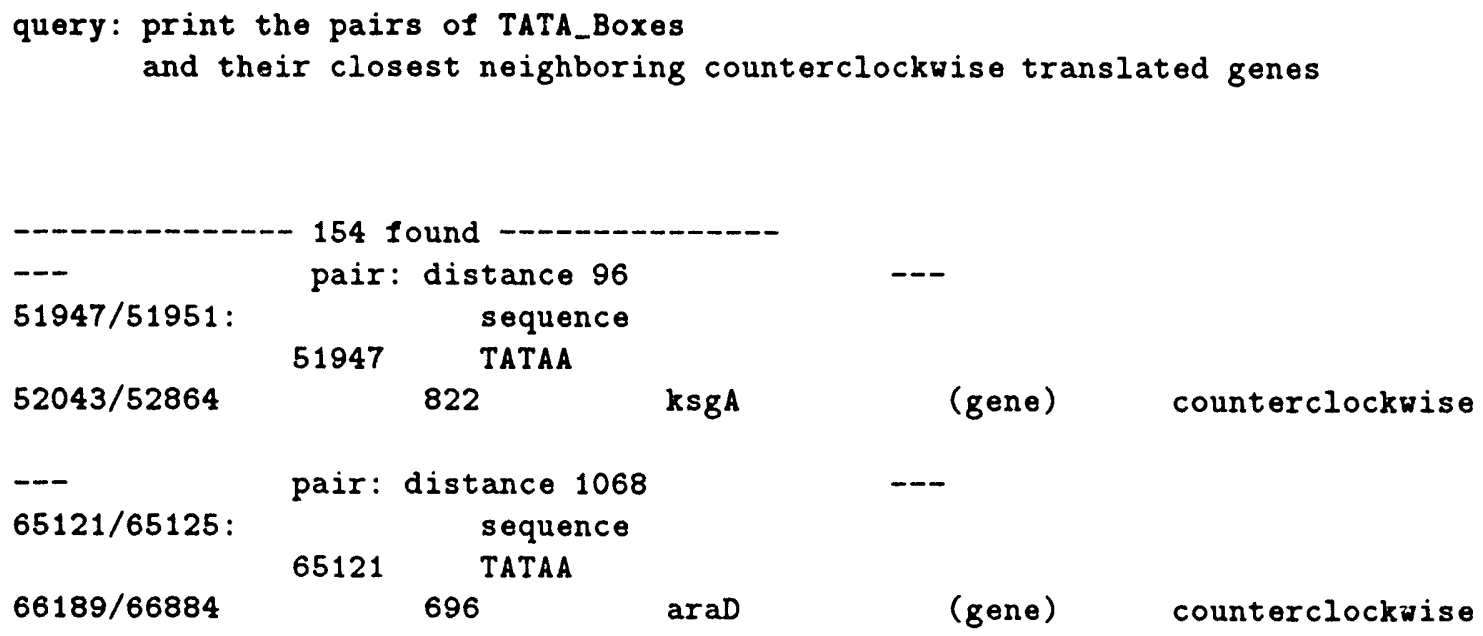

10.9 Print the pairs of TATA_Boxes and their closest neighboring counterclockwise translated genes sorted by distance

query: print the pairs of TATA_Boxes

and their closest neighboring counterclockwise translated genes sorted by distance

pair: distance 11
1322911/1322915: 154 found
1322911 TATAA
$711799 / 711803:$ pair: distance 12
711799 sequence
TATAA




\section{Locating Amino Acid Patterns In Translated Genes}

\subsection{Standard Patterns or Prefixes}

11.1.1 Print occurrences of amino acid pattern C ( ?? | ??? ) C in translated genes query: print occurrences of amino acid pattern C ( ?? I ????) C in translated genes

$\begin{array}{cccc}2069825 / 2069842 & 18 & \text { (expressed) clockwise } \\ 1998522 / 1998539 & 18 & \text { C YIGH C } & \text { amn } \\ 3538241 / 3538258 & 18 & \text { araH } & \text { (expressed) counterclockwise } \\ 3538244 / 3538258 & 15 & \text { C IRRC C } & \text { (expressed) counterclockwise } \\ 1799404 / 1799418 & \text { C IR C } & \text { aroB } & \text { (expressed) counterclockwise } \\ & \text { C EDI C } & \text { aroH } & \text { (expressed) clockwise }\end{array}$

\subsection{Zinc Fingers}

11.2.1 Print occurrences of amino acid pattern $\mathrm{C}$ ( ??? |??? )

C ????????? ( ? | (?? | ( ?? | ???? ) ) )

H ( ??? | ??? ) H in translated genes

query: print occurrences of amino acid pattern

C (??? I ????)

C ?????????? ( ? | ( ?? | ( ??? | ???? ) ) )

H (??? l ????) H

in translated genes 


\section{Assessing the Distribution of Objects}

\subsection{Count the Occurrences of Objects on the Chromosome}

12.1.1 Count the occurrences of pattern TGGATGGA in 20-minute pieces of the genome

query: count the occurrences of pattern TGGATGGA

in 20 minute pieces of the genome

$\begin{array}{llll}0 / 934519 & 934520 & 6 & \text { (count) } \\ 934520 / 1869039 & 934520 & 1 & \text { (count) } \\ 1869040 / 2803559 & 934520 & 2 & \text { (count) } \\ 2803560 / 3738079 & 934520 & 5 & \text { (count) } \\ 3738080 / 4672599 & 934520 & 3 & \text { (count) }\end{array}$

12.1.2 Count the occurrences of pattern GATC in 10-minute pieces of the genome starting at oriC

query: count the occurrences of pattern GATC

in 10 minute pieces of the genome starting at oric

$\begin{array}{llll}214981 / 682240 & 467260 & 471 & \text { (count) } \\ 682241 / 1149500 & 467260 & 549 & \text { (count) } \\ 1149501 / 1616760 & 467260 & 343 & \text { (count) } \\ 1616761 / 2084020 & 467260 & 396 & \text { (count) } \\ 2084021 / 2551280 & 467260 & 363 & \text { (count) } \\ 2551281 / 3018540 & 467260 & 443 & \text { (count) } \\ 3018541 / 3485800 & 467260 & 601 & \text { (count) } \\ 3485801 / 3953060 & 467260 & 711 & \text { (count) } \\ 3953061 / 4420320 & 467260 & 968 & \text { (count) } \\ 4420321 / 214980 & 467260 & 697 & \text { (count) }\end{array}$

12.1.3 Count all restriction fragments for enzymes \{Aat2, EcoR1\} in 10 equal partitions of the genome

query: count all restriction fragments for enzymes \{Aat2, EcoR1\}

in 10 equal partitions of the genome

$\begin{array}{llll}0 / 467259 & 467260 & 65 & \text { (count) } \\ 467260 / 934519 & 467260 & 36 & \text { (count) } \\ 934520 / 1401779 & 467260 & 39 & \text { (count) } \\ 1401780 / 1869039 & 467260 & 21 & \text { (count) }\end{array}$




$\begin{array}{llll}1869040 / 2336299 & 467260 & 23 & \text { (count) } \\ 2336300 / 2803559 & 467260 & 40 & \text { (count) } \\ 2803560 / 3270819 & 467260 & 31 & \text { (count) } \\ 3270820 / 3738079 & 467260 & 57 & \text { (count) } \\ 3738080 / 4205339 & 467260 & 77 & \text { (count) } \\ 4205340 / 4672599 & 467260 & 66 & \text { (count) }\end{array}$

12.1.4 Count the translated counterclockwise genes in (10 equal partitions of the genome starting at oriC)

query: count the translated counterclockwise genes in

(10 equal partitions of the genome starting at oric)

$\begin{array}{llll}214981 / 682240 & 467260 & 19 & \text { (count) } \\ 682241 / 1149500 & 467260 & 21 & \text { (count) } \\ 1149501 / 1616760 & 467260 & 19 & \text { (count) } \\ 1616761 / 2084020 & 467260 & 34 & \text { (count) } \\ 2084021 / 2551280 & 467260 & 18 & \text { (count) } \\ 2551281 / 3018540 & 467260 & 23 & \text { (count) } \\ 3018541 / 3485800 & 467260 & 50 & \text { (count) } \\ 3485801 / 3953060 & 467260 & 76 & \text { (count) } \\ 3953061 / 4420320 & 467260 & 31 & \text { (count) } \\ 4420321 / 214980 & 467260 & 28 & \end{array}$

12.1.5 Count the genes in 10 equal partitions of the genome query: count the genes in 10 equal partitions of the genome

$\begin{array}{llrl}0 / 467259 & 467260 & 137 & \text { (count) } \\ 467260 / 934519 & 467260 & 103 & \text { (count) } \\ 934520 / 1401779 & 467260 & 89 & \text { (count) } \\ 1401780 / 1869039 & 467260 & 47 & \text { (count) } \\ 1869040 / 2336299 & 467260 & 64 & \text { (count) } \\ 2336300 / 2803559 & 467260 & 73 & \text { (count) } \\ 2803560 / 3270819 & 467260 & 91 & \text { (count) } \\ 3270820 / 3738079 & 467260 & 119 & \text { (count) } \\ 3738080 / 4205339 & 467260 & 161 & \text { (count) } \\ 4205340 / 4672599 & 467260 & 122 & \end{array}$

12.1.6 Count the translated genes in $100 \mathrm{~kb}$ pieces of the genome query: count the translated genes in $100 \mathrm{~kb}$ pieces of the genome 


$\begin{array}{llll}0 / 99999 & 100000 & 37 & \text { (count) } \\ 100000 / 199999 & 100000 & 27 & \text { (count) } \\ 200000 / 299999 & 100000 & 14 & \text { (count) } \\ 300000 / 399999 & 100000 & 7 & \text { (count) } \\ 400000 / 499999 & 100000 & 19 & \text { (count) } \\ 500000 / 599999 & 100000 & 16 & \text { (count) } \\ 600000 / 699999 & 100000 & 14 & \text { (colnt) } \\ 700000 / 799999 & 100000 & 32 & \text { (count) } \\ 800000 / 899999 & 100000 & 8 & \text { (count) } \\ 900000 / 999999 & 100000 & 14 & \text { (count) } \\ 1000000 / 1099999 & 100000 & 13 & \end{array}$

12.1.7 Count the clockwise translated genes in 10 equal partitions of the genome query: count the clockwise translated genes in 10 equal partitions of the genome

$\begin{array}{llll}0 / 467259 & 467260 & 83 & \text { (count) } \\ 467260 / 934519 & 467260 & 47 & \text { (count) } \\ 934520 / 1401779 & 467260 & 41 & \text { (count) } \\ 1401780 / 1869039 & 467260 & 15 & \text { (count) } \\ 1869040 / 2336299 & 467260 & 21 & \text { (count) } \\ 2336300 / 2803559 & 467260 & 12 & \text { (count) } \\ 2803560 / 3270819 & 467260 & 31 & \text { (count) } \\ 3270820 / 3738079 & 467260 & 19 & \text { (count) } \\ 3738080 / 4205339 & 467260 & 54 & \text { (count) } \\ 4205340 / 4672599 & 467260 & 47 & \end{array}$

\subsection{Compute the Adjusted Counts of Objects}

12.2.1 Print the adjusted counts of genes in 10 equal partitions of the genome query: print the adjusted counts of genes in 10 equal partitions of the genome

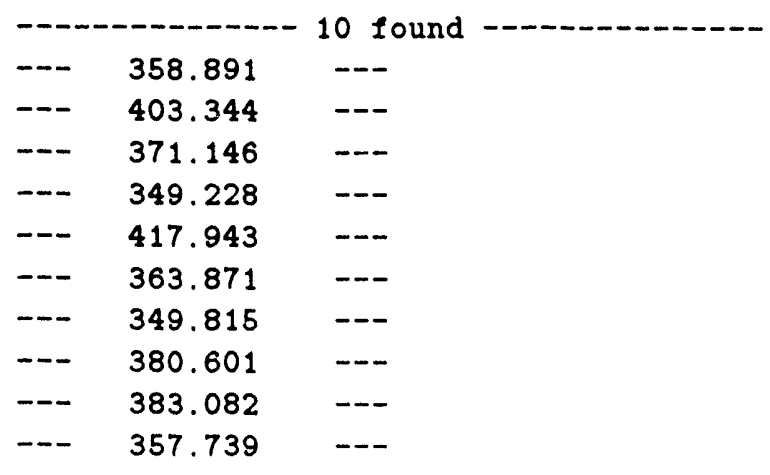


12.2.2 Print the adjusted counts of translated counterclockwise genes in (10 equal partitions of the genome starting at oriC)

query: print the adjusted counts of translated counterclocknise genes in

(10 equal partitions of the genome starting at oric)

\begin{tabular}{|c|c|}
\hline--- & 76.9559 \\
\hline--- & 81.998 \\
\hline- & 113.418 \\
\hline-- & 170.588 \\
\hline--- & 109.91 \\
\hline & 96.4954 \\
\hline- & 188.821 \\
\hline- & 229.787 \\
\hline- & 64.6265 \\
\hline - & 79.509 \\
\hline
\end{tabular}

12.2.3 Print the adjusted counts of occurrences of pattern CCYGG in 4 equal partitions of the genome starting at oriC

query: print the adjusted counts of occurrences of pattern CCYGG in

4 equal partitions of the genome starting at oric

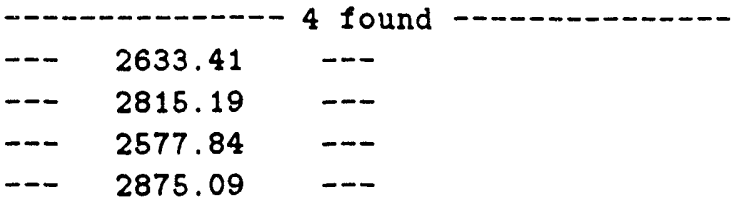

\section{Defining New Concepts}

\subsection{Defining a Region of Interest}

13.1.1 "Define Interesting to be the region from 87 minutes to 88 minutes"

query: define macro Interesting the region from 87 minutes to 88 minutes

Macro Interesting defined.

13.1.2 "Verify the location of region Interesting"

query: print Interesting 


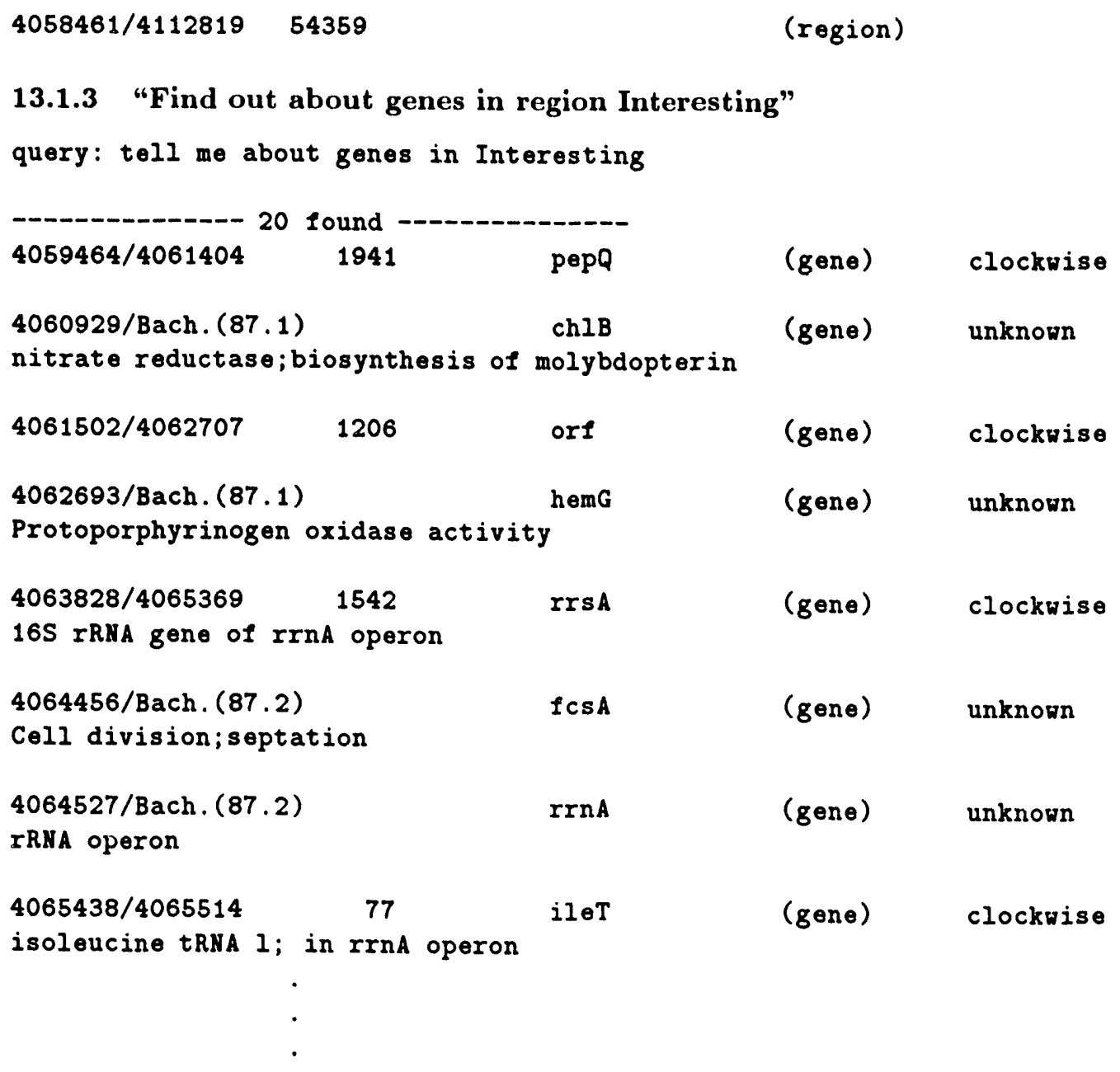

\subsection{Defining a Name for a Pattern}

13.2.1 "Define HairpinLoop to be the name of a particular type of hairpin loop" query: define macro HairpinLoop p1=6..8 $3 \ldots 20 \%$ p 1

Macro HairpinLoop defined.

13.2.2 "Locate all occurrences of hairpin loops of desired type in region Interesting, ordered by location"

query: print all occurrences of pattern HairpinLoop in Interesting

218 found

$\begin{array}{cl}\text { 4058491/4058517: } & \text { sequence } \\ 4058491 & \text { CCGCAG CTTCAATGGTTTTTA CTGCGG } \\ 4058556 / 4058575: & \text { sequence } \\ 4058556 & \text { ACCATC CCTTTAGC GATGGT } \\ 4058575 / 4058594: & \text { sequence } \\ 4058575 & \text { TGAAGC TCATGGTG GCTTCA } \\ 4058943 / 4058961: & \text { sequence }\end{array}$




\begin{tabular}{|c|c|}
\hline 4058943 & CCATTG ACGGCAG CAATGG \\
\hline 4059026/4059049: & sequence \\
\hline 4059026 & CTGTTC TTCAGGAACGAG GAACAG \\
\hline 4059060/4059078: & sequence \\
\hline 4059060 & TCGGTG ATATCAG CACCGA \\
\hline $4059086 / 4059114:$ & sequence \\
\hline 4059086 & GGCTGC TTTGTTCGAACGCAGCA GCAGCC \\
\hline $4059086 / 4059114:$ & sequence \\
\hline 4059086 & GGCTGCT TTGTTCGAACGCAGC AGCAGCC \\
\hline 4059087/4059110: & sequence \\
\hline 4059087 & GCTGCT TTGTTCGAACGC AGCAGC \\
\hline 4059087/4059113: & sequence \\
\hline 4059087 & GCTGCT TTGTTCGAACGCAGC AGCAGC \\
\hline 4059300/4059316: & sequence \\
\hline 4059300 & ATCTGG TCGTA CCAGAT \\
\hline 4059300/4059316: & sequence \\
\hline 4059300 & ATCTGGT CGT ACCAGAT \\
\hline$\cdot$ & \\
\hline & \\
\hline$\cdot$ & \\
\hline
\end{tabular}

\subsection{Defining a New Concept in Terms of an Existing Objent}

13.3.1 "Define Upstream to be the region 100 base pairs upstream of an existing object"

query: define macro Upstream(G) the region from the start of G - 100

to the start of $G-1$

Macro Upstream defined.

13.3.2 "Define Initial to be the first 80 base pairs in an existing object" query: define macro Initial(G) the region from the start of $G$
to the start of $G+80$

Macro Initial defined.

13.3.3 "Use the new concepts Upstream and Initial to investigate each clockwise gene $\mathrm{X}$ in region Interesting"

query: for each clockwise gene in Interesting $X$, fprint $X$; print all sequences of length at least 5 common to \{Upstream $(X)$, Upstream $(X)$, Initial $(X)$ \} using both strands\}
$4059464 / 4061404$
1941
pepQ
(gene)
clockwise

3 found

$\begin{array}{cl}\text { 4059380/4059384: } & \text { sequence } \\ 4059380 & \text { ATCAC } \\ 4059396 / 4059400: & \text { sequence } \\ 4059396 & \text { ATCAC } \\ 4059469 / 4059473: & \text { sequence }\end{array}$




\begin{tabular}{|c|c|}
\hline 4059469 & ATCAC \\
\hline 4059384/4059388: & sequence \\
\hline 4059384 & CGCTC \\
\hline 4059400/4059404: & sequence \\
\hline 4059400 & CGCTC \\
\hline 4059480/4059484: & sequence \\
\hline 4059480 & CGCTC \\
\hline 4059443/4059447: & sequence \\
\hline 4059443 & AAAAA \\
\hline 4059444/4059448: & sequence \\
\hline 4059444 & AAAAA \\
\hline 4059445/4059449: & sequence \\
\hline 4059445 & AAAAA \\
\hline 4059459/4059463: & sequence \\
\hline 4059459 & AAAAA \\
\hline 4059488/4059492: & sequence \\
\hline 4059488 & AAAAA \\
\hline
\end{tabular}

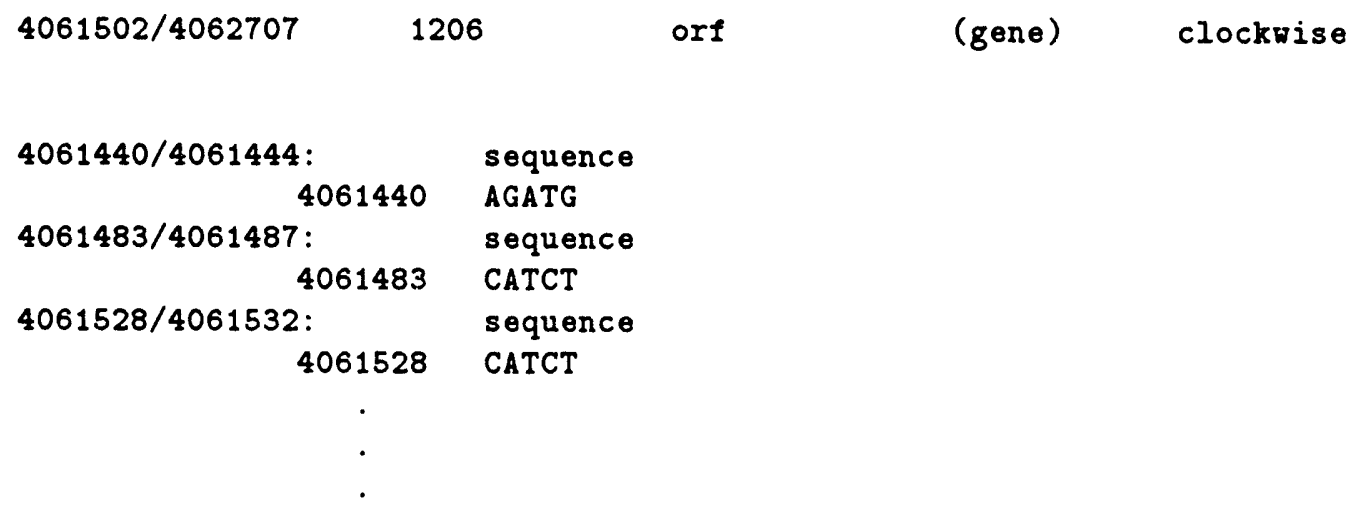



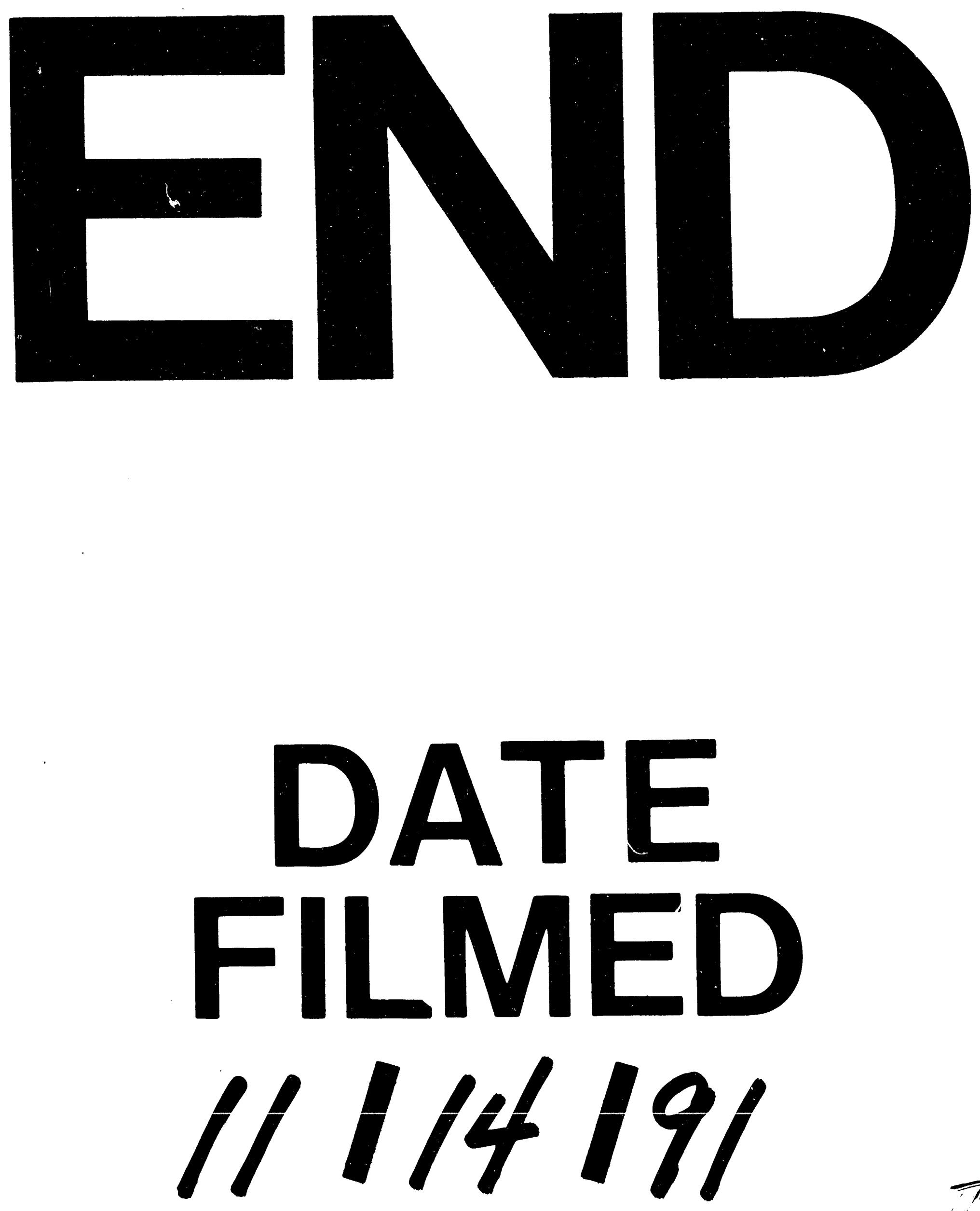

II 
